\title{
Characterization and gene expression analysis of the two main Th17 cytokines (IL-17A/F and IL-22) in turbot, Scophthalmus maximus.
}

Costa MM. ${ }^{a}$, Pereiro P. ${ }^{a}$, Wang T. ${ }^{b}$, Secombes CJ. ${ }^{b}$, and Figueras A. ${ }^{a}$ Novoa B. ${ }^{a} *$

a. Instituto de Investigaciones Marinas (IIM), CSIC, Eduardo Cabello 6, 36208 Vigo, Spain.

b. Scottish Fish Immunology Research Centre, Institute of Biological and Environmental Sciences, University of Aberdeen, Aberdeen AB24 2TZ, UK.

*Corresponding author 


\begin{abstract}
This report describes the cloning, characterization and gene expression pattern of two Th17 cytokines, interleukin (IL)-17A/F and -22, in turbot Scophthalmus maximus. The turbot IL-17A/F cDNA contains a 516 bp open reading frame encoding a deduced IL-17A/F protein of 171 amino acid (aa) residues, containing a predicted signal peptide of 31 aa. Turbot IL-22 had a 564 bp ORF coding for a 187 aa protein with a 33 aa signal peptide. The turbot IL-22 protein contained a typical IL-10 family signature. Both cytokines had highest expression levels in the intestine followed by head kidney and gills. Stimulation with the Gram negative bacterium Aeromonas salmonicida was able to modulate IL-17A/F and IL-22 expression in head kidney, spleen and liver but not the intestine. PMA and PHA were also able to induce the expression of both cytokines, suggesting that, as expected, T-cells are likely the main producers of these molecules in turbot as in mammals.
\end{abstract}

Keywords: IL-22, IL-17, Th-17 response, mucosal-associated immunity 


\section{Highlights}

- We characterized two Th17 cytokines, (IL)-17A/F and -22 in turbot

- Both cytokines had highest basal expression levels in the intestine

- Infection with A.salmonicida was able to modulate their expression in kidney and spleen

- PMA and PHA were also able to induce the expression of both cytokines 


\section{Introduction}

Classically, two different types of $\mathrm{T}$ helper (Th) response are known. The Th-1 response is involved in the fight against intracellular pathogens while the Th-2 plays a role in the elimination of extracellular microorganisms and parasites. Cells belonging to Th-1 subtype release interferon- $\gamma$ (IFN- $\gamma$ ) and interleukin-2 (IL-2) whilst the Th-2 subset secretes IL-4 and IL-13 (Mosmann and Coffman, 1989). Recently, a third subtype of Th-cells, Th-17, has been discovered (Harrington et al., 2005, 2006; Fouser et al., 2008) with an important role in the response against extracellular bacteria and fungi. Two cytokines that are central to the function of this subset are IL-17 and IL-22.

IL-17 is the founding member of a newly identified IL-17 family which in mammals comprises a total of six different cytokines (IL-17A-F) and five receptors (Gaffen et al., 2006; Kramer et al., 2007). Each of them has a different pattern of expression and a distinct function. IL17A (often simply called IL-17) was the first to be discovered and it shares more than half of its protein sequence with IL-17F. IL-17A and F can be produced by a wide cellular repertoire, including $\mathrm{T}$ and NK cells, and neutrophils (Roark et al., 2008). These cytokines induce a number of different actions, such as macrophage and neutrophil recruitment, granulocyte colony stimulation, inflammation and autoimmune diseases (Gaffen et al., 2006). IL-17 A and F can be also produced by subsets of $\gamma \delta \mathrm{T}$ cells, which can be activated by molecules involved in the innate response, such as IL-1 $\beta$, that are released from damaged cells (Swamy and Hayday, 2011). This fact and their ability to recruit macrophages and neutrophils, illustrates the important role of IL-17A and F in the first line of defense. Cells presented in the mucosal epithelial and those belonged to the immune system are essential for host defense against infection and for the autoimmunity development (Abraham and Medzhitov, 2011). In the absence of IL-17A cells are susceptible to bacterial and fungal infections and increases those inflammatory process which produce a perturbation of the mucosal homeostasis (Ishigame et al., 2009). However, this cytokine has also a dual role. Higher IL-17A expression levels were detected in uncontrolled inflammation process such as psoriasis, rheumatoid arthritis or inflammatory bowel disease (Fonseca-Camarillo et al., 2011).

In fish, transcripts with homology to IL-17A or F have been found. Their close location on the same chromosome in addition to the high homology of both isoforms, has made identification of direct homologues difficult. Thus, these genes in fish have been termed IL-17A/F (Gunimaradevi et al., 2006). Different isoforms of IL-17A/F have been described in several fish species. IL-17A/F1, 2 and 3 have been reported in zebrafish, Danio rerio, (Gunimaladevi et al., 2006), Japanese pufferfish, Takifugu rubripes, (Korenaga et al., 2010) and medaka, Oryzias latipes (Kono et al., 2010). An IL17A/F1 isoform has also been found in halibut, Hipoglossus hipoglossus and an IL-17A/F2 isoform in rainbow trout, Oncorhynchus mykiss (Monte et al., in press). 
IL-22 is a member of the IL-10 cytokine family which also includes IL-10, IL-19, IL-20, IL24 and IL-26. Since it shares sequence homology with IL-10, it was originally named IL-10 related T cell-derived inducible factor (IL-TIF) (Dumoutier et al., 2000). In mammals, IL-22 is expressed by many different types of lymphocytes, including those involved in the innate and adaptive response (Wolk and Sabat, 2006). Its expression by $\mathrm{CD}^{+}$cells (especially Th-17 and Th-22 subsets), $\gamma \delta \mathrm{T}$ cells, NK cells such as NKp46 ${ }^{+}$cells or NK22 cells (Sanos et al., 2009), particularly in the intestine, and by LTi and LTi-like cells, suggests an important role of this cytokine in the mucosal-associated lymphoid tissues (Cella et al., 2009). Production of IL-22 does differ relative to IL-17A and F. For example, in Th-17 cells IL-17A and F expressing cells can be obtained by in vitro co-stimulation with TGF $\beta$ and IL-6; however, these conditions do not seem to be enough to produce IL-22. This is because TGF $\beta$ inhibits IL-22 production while in presence of IL-23 and IL-1 $\beta$, its expression is increased (Ghoreschi et al., 2010).

IL-22 is involved in several chronic inflammatory diseases such as psoriasis, rheumatoid arthritis and intestinal bowel disease (IBD) (Wolk et al., 2006; Ouyang, 2010). Different models have identified both inflammatory and protective roles for IL-22. This cytokine has also a crucial function in pathogen-mediated inflammation in the gastro-intestinal tract. Experimental infections performed in mice with Toxoplasma gondii did not show any variation in IL-22 levels when the parasite was injected into the peritoneal cavity. However, oral inoculation showed high levels of protection in $I L-22^{-}$mice in comparison with wild type animals (Zenewicz and Flavell, 2011). Moreover, IL-22 helps in the maintenance of epithelial barriers preventing bacterial dissemination and inducing the expression of several antimicrobial molecules and pro-inflammatory cytokines (Wolk et al., 2004; Zheng et al., 2008; Monte et al., 2011)

IL-22 has already been described in different fish species such as fugu, Takifugu rubripes (Zou et al., 2004), zebrafish, Danio rerio (Igawa et al., 2006), Atlantic cod, Gadus morhua, haddock, Melanogrammus aeglefinus (Corripio-Miyar et al., 2009) and rainbow trout, Oncorhynchus mykiss (Monte et al., 2011). In the current paper we have described the sequences of two Th-17 cytokines, IL-17A/F and IL-22, in one of the most important cultured marine fish species turbot, Scophthalmus maximus. Their basal gene expression was analyzed in different tissues in order to identify the most important sites of production of these Th-17 cytokines. The modulation of both molecules was observed in vitro and in vivo after stimulation with PMA/PHA or with Aeromonas salmonicida 
respectively. The obtained results contribute to our knowledge on the mucosal-associated defense in this fish species which is of great interest in the aquaculture sector. 


\section{Material and methods}

2.1. Fish.

Turbot, Scophthalmus maximus, were obtained from a commercial fish farm (Comar, Galicia, NW Spain). The animals were maintained in an open seawater filtered system at $15^{\circ} \mathrm{C}$ with aeration. They were fed once daily with a standard commercial diet. Prior to the experimental work, the fish were acclimatized to laboratory conditions for a minimum period of one week and their general status was verified every day. No abnormal observations were detected.

\subsection{Homology cloning of turbot $I L-17 A / F$ and $I L-22$.}

A tBlastN search of the Pleuronectiforme NCBI EST database using the rainbow trout IL-17A/F and IL-22 protein sequences (Acc. No. AJ580842 and CAO02398) as queries, returned no ESTs from turbot but two ESTs from halibut and tilapia showed homology to IL-17A and F and IL-22 respectively. Multiple alignments of IL-17A and F and IL-22, including the translation of the two identified ESTs, were constructed in order to detect conserved regions. Primers were designed against the ESTs at the conserved regions and used for PCR to amplify a fragment from turbot DNA samples. Cloning and sequence analysis of the amplified products revealed that they were indeed from turbot IL-17A/F and IL-22 genes. To obtain the ORF of both cytokines, 5'-RACE was carried out in both cases and in addition 3'-RACE was performed to complete the 3' end of the IL-17A/F sequence. SMART cDNA was produced for this purpose, from head kidney and intestine, and was synthesized as described previously (Wang and Secombes, 2003). The IL-17A/F and IL-22 primer sequences are shown in Tables $1 \mathrm{~A}$ and $1 \mathrm{~B}$, respectively.

\subsection{Sequence analysis and $3 D$ structure.}

A multiple sequence alignment was generated using ClustalW2 (Chenna et al. 2003) and the translation was performed using ExPaSy tools (http://us.expasy.org/tools). Signal peptides were predicted using SignalP 3.0 (Emanuelsson et al. 2007). Global sequence comparison was performed using the MatGAT program (Campanella et al. 2003). Phylogenetic trees were created by the neighbour-joining method using the MEGA program (Tamura et al. 2011), and were bootstrapped 10,000 times. An alignment with the human IL-17A and IL-22 was conducted using Modweb and ModBase (Pieper et al., 2011) and Pymol (The PyMOL Molecular Graphics System, Version 1.2r3pre, Schrödinger, LLC.) The protein structure modelling was conducted using 3D-JIGSAW (http://bmm.cancerresearchuk.org/ 3djigsaw/) and I-TASSER (Zhang 2007; Roy et al., 2010) 
selecting the model with the best C-score. The TM-score was used as an indication of structural similarity.

\subsection{Tissue distribution.}

Heart, brain, muscle, liver, spleen, gills, head kidney and intestine from five pools of 4 healthy fish each (size 2-3 g) were collected in order to analyze the expression level in different turbot tissues. Samples were kept in TRIzol (Invitrogen) until processing (see below).

\subsection{Expression of IL-17A/F and IL-22 upon in vivo bacterial infection.}

A pathogenic strain (VT45.1) of the Gram-negative pathogen Aeromonas salmonicida (kindly donated by Dr. M. L. Lemos; University of Santiago de Compostela, Spain) was injected intraperitoneally into turbot (100 $\mu \mathrm{l} / \mathrm{fish} ; 2.5 \times 10^{6} \mathrm{cfu} / \mathrm{ml}$ in PBS) of 2-3 g. A separate group of fish was injected with PBS (100 $\mu$ L/fish) as a control. Five pools of 4 fish each were killed at different time points $(3,8,24$ and $48 \mathrm{~h})$ post-infection and head kidney, spleen, liver and intestine were collected for total RNA extraction. The expression level of IL-17A/F and IL-22 was analyzed by real-time PCR (see below).

\subsection{Preparation of head kidney, spleen and intestinal leukocytes.}

Fish of 200g were anesthetized using 2-phenoxyethanol (Sigma), killed and head kidney, spleen and intestine aseptically removed. A total leukocyte suspension from head kidney and spleen were prepared by passing the tissues through a $100-\mu$ m nylon mesh with medium that contained L-15, 100 $\mathrm{U} / \mathrm{ml}$ penicillin and $100 \mathrm{mg} / \mathrm{ml}$ streptomycin (P/S), 0.5\% FCS and $10 \mathrm{U} / \mathrm{ml}$ heparin (all components were from Invitrogen). The prepared cell suspensions were layered onto a $51 \%$ Percoll and centrifuged to separate the red blood cells. Following centrifugation, the intermediate leukocyte layer was collected and washed twice with L-15 medium supplemented with $2 \%$ FCS and P/S, and centrifuged again at $400 \mathrm{xg}\left(4^{\circ} \mathrm{C}\right)$ for $10 \mathrm{~min}$.

The gut associated lymphoid tissue (GALT) was obtained from the intestine following the mechanical methodology previously described by Salinas et al. (2007). Briefly, intestines were harvested from freshly killed fish and passed through a 100- $\mu$ m nylon mesh with cold RPMI-1640 culture medium containing $0.35 \%$ sodium chloride and $10 \mathrm{U} / \mathrm{ml}$ heparin. The cell suspensions were washed twice by centrifugation at $400 \mathrm{xg}$ for $10 \mathrm{~min}$ at $23^{\circ} \mathrm{C}$. 
After centrifugation the cells were resuspended in L-15, 10\% FCS and P/S or RPMI with sodium chloride (HK and splenocytes or intestinal cells respectively). Viable cells were counted by trypan blue (Invitrogen) exclusion using a haemocytometer. The cell suspensions were adjusted to the required concentration $\left(1.5 \times 10^{6}\right.$ cells $\left./ \mathrm{ml}\right)$ in L-15 or RPMI medium supplemented with $10 \%$ FCS and $\mathrm{P} / \mathrm{S}$, and cells seeded into 6-well plates at $3 \mathrm{ml}$ per well.

\subsection{Modulation of $I L-17 A / F$ and $I L-22$ in vitro.}

Head kidney, spleen and intestine cell suspensions from five healthy fish, prepared as above, were stimulated with $100 \mu \mathrm{l}$ of phorbol-12-myristate-13-acetate (PMA; $100 \mathrm{ng} / \mathrm{ml}$ final concentration) or phytohemagglutinin (PHA) solution (from red kidney bean Phaseolus vulgaris; $10 \mu \mathrm{g} / \mathrm{ml}$ final concentration). Both chemicals were obtained from Sigma-Aldrich and they were diluted in complete medium (L-15 + P/S + 10\% FCS) before addition to the cells. A similar volume of medium was added to the cells in the control wells. An additional in vitro stimulation was carried out with heatkilled bacteria. An overnight culture of A. salmonicida was resuspended in $20 \mathrm{ml}$ of sterile PBS and heated 10 minutes at $100^{\circ} \mathrm{C}$. A volume of $100 \mu \mathrm{l}$ was inoculated into 6 -well plates to the cell cultures. All plates were kept at $20^{\circ} \mathrm{C}$ for 3,6 and $24 \mathrm{~h}$ after stimulation. The cells were then centrifuged at $400 \mathrm{xg}\left(4^{\circ} \mathrm{C}\right)$ for $5 \mathrm{~min}$, the supernatants removed, and cells resuspended in TRIzol (Invitrogen) and stored at $-80^{\circ} \mathrm{C}$ until their RNA isolation.

\subsection{RNA isolation, cDNA synthesis and $q P C R$.}

Total RNA was isolated using Trizol reagent (Invitrogen) following the manufacturer's instructions. Total RNA was treated with DNase I (RNase-Free DNase set; Qiagen) to remove any possible contaminating DNA. Purification of treated RNA was carried out using an RNeasy mini kit (Qiagen). First-strand cDNAs were synthesized with SuperScript III (Invitrogen) using $1 \mu \mathrm{g}$ of total RNA.

Specific primers of each gene were designed and checked to ensure similar efficiencies in amplification reaction according to the protocol described by Schmittgen and Livak (2008). A total of $0.5 \mu \mathrm{l}$ of each primer $(10 \mu \mathrm{M})$ was mixed with $12.5 \mu 1$ of SYBR green PCR master mix (Applied Biosystems) in a final volume of $25 \mu$. The standard cycling conditions were $95^{\circ} \mathrm{C}$ for $10 \mathrm{~min}$, followed by 40 cycles of $95^{\circ} \mathrm{C} 15 \mathrm{~s}$ and $60^{\circ} \mathrm{C}$ for $1 \mathrm{~min}$. The comparative $\mathrm{Ct}$ method $(2-\Delta \Delta \mathrm{Ct}$ method) was used to determine the expression level of analyzed genes (Schmittgen and Livak; 2008). The expression of IL-17A/F and IL-22 genes was normalized to that of the EF-1 $\alpha$ gene as a control housekeeping gene. Fold units were calculated by dividing the normalized expression values in the different samples by the normalized expression values obtained in the controls. In the tissue 
distribution analysis, the expression of transcripts was also normalized against that of the housekeeping gene and expressed as arbitrary units, where 1 arbitrary unit was equal to the average expression level in brain for IL-17A/F and IL-22, respectively, which had the lowest expression level among the tissues studied.

\subsection{Statistical analysis.}

Data were analyzed using the Student's t-test or paired t-test, the latter for those data sets which were related. Results were expressed as the mean + standard error of the different samples (fish or pools). Differences were considered statistically significant at $\mathrm{p}<0.05$.

\section{Results}

\subsection{Cloning of IL-17A/F and IL-22, and $3 D$ structure.}

The turbot IL-17A/F cDNA sequence (GenBank Accesion No.: JQ349069) contained an open reading frame (ORF) of 516 nucleotides which translate into a 171 aa peptide, and a 5'UTR of 144 nucleotides (Figure 1A), with an incompletely sequenced 3' UTR region. A signal peptide of 31 aa was predicted at the $\mathrm{N}$-terminal of the protein, suggesting it is secreted. Three conserved serine residues were present in the mature protein, as well as three potential glycosylation sites, with the second showing a high degree of conservation. Four conserved cysteines, which participate in two disulphide bonds, were also found (Figure 2A). The 3D structural analysis of turbot IL-17A/F revealed that the best template in the database was human IL-17A (it possesses a total of four copies). Even when the alignment of the turbot IL-17A/F structure with the human IL-17 did not cover all the turbot sequence because human IL-17 lacks of alpha helix, the rest of the structure showed a perfect superposition in the beta-sheets, indicating that turbot molecule has a cystine-knot structure (Figure 3).

The turbot IL-22 cDNA sequence (GenBank Accesion No.: JQ349070) contained a 5'UTR of 60 bp, an ORF of $564 \mathrm{bp}$ which encodes a 187 aa protein and a 3'UTR of $357 \mathrm{bp}$ followed by a poly A tail. The 3' UTR region contains 5 mRNA instability motifs (ATTTA) as well as a polyadenylation signal (AATAAA). A signal peptide of 33 aa was located in the amino terminus of the protein (Figure 1B), indicating it is a secreted protein. A multiple alignment of the aa sequences of known IL-22 molecules revealed that the IL-10 family signature is relatively well conserved between species (Fig. 2B). Turbot IL-22 possessed four conserved cysteine residues which participate in two disulphide bonds (Figure 2B). The tertiary structure of the turbot IL-22 was modelled with a high 
confidence (C-score of 0.72 and a TM-score of 0.81 ) and revealed a high similarity between the turbot and human structures (Fig. 3).

\subsection{Homology and phylogenetic comparison.}

The phylogenetic tree constructed with IL-17 sequences of fish and other species showed three main clusters corresponding with the three representative IL-17 family members: IL-17 A/F, IL-17 C and IL-17 D (Figure 4A). The IL-17 A/F cluster had two main branches corresponding, mainly, with the mammals/birds and fish groups. Turbot IL-17A/F was located within the IL-17A/F1 clade, close halibut and medaka IL-17A/F1. These results and our homology analysis (Table 2) clearly show that turbot IL-17A/F belongs to the fish IL-17A/F1 group. The turbot IL-22 phylogenetic tree was constructed using fish and mammalian IL-22 sequences and also sequences of other members of the IL-10 cytokine family (Figure 4B). Three main clusters were found corresponding to the IL-10, IL22 and IL-19/ 20/ 24 clades, with a fourth clade consisting of tetrapod IL-26 molecules also well supported. Turbot IL-22 was located in the IL-22 clade and was placed close to the other fish sequences. The homology analysis revealed that identities/similarities of the IL-22 amino acid sequences were between $46.3 \%$ and $54.2 \%$ for the identity and higher than $60 \%$ for the similarity (Table3).

\subsection{Expression analysis.}

Real time PCR analysis revealed that IL-17A/F and IL-22 expression was highest in the intestine (Figure 5). Relatively high expression was also seen in head kidney and gills for both cytokines. Most of the tissues showed detectable expression levels of IL-17A/F and IL-22, with heart having the lowest expression level for both cytokines.

The two major immune organs (head kidney and spleen) showed a modulation of IL-17A/F and IL-22 expression after in vivo stimulation with the bacterium Aeromonas salmonicida (Figure 6). Maximum expression was found after $24 \mathrm{~h}$ of stimulation in the head kidney, with a $\sim 5$-fold increase over the control values. The response in the spleen peaked earlier, showing a maximum response at $8 \mathrm{~h}$ after stimulation, with a significant increase also present at $3 \mathrm{~h}$ for IL-17A/F. The expression of both cytokines was also analyzed in liver and intestine, which had low and high basal expression respectively. IL-17A/F expression was not significantly modulated in liver relative to the control. However, a strong stimulation of IL-22 expression was seen in this tissue, where a 18-fold increase over the control was seen $8 \mathrm{~h}$ after stimulation. In the intestine, the organ with the highest expression level for both cytokines in normal conditions, neither IL-17A/F nor IL-22 expression was altered 
after a bacterial stimulation in a significant manner, although a 2-fold and 3-fold increase were observed in IL-17A/F and IL-22 at 3 and 8 hours respectively.

Total leukocytes from head kidney, intestine and spleen were collected, and two different stimulants (PMA and PHA) and a heat killed bacteria were used to study the expression modulation of IL-17A/F and IL-22 under in vitro conditions (Figures 8 and 7). PMA was the better inducer of IL-17A/F and IL-22 expression, and in general highest levels were seen at 3-6h post-stimulation with cells from all three tissues. Expression levels waned by $24 \mathrm{~h}$ post-stimulation, although still significantly elevated in spleen for both genes and intestine for IL-17A/F. PHA was less effective but did induce increased expression of IL-17A/F in head kidney and IL-22 in spleen at $24 \mathrm{~h}$ poststimulation, perhaps via an indirect effect. In spite of some apparent increases are present in Figure 8, the heat killed bacteria A. salmonicida, was not able to induce the expression of these Th-17 cytokines in a significant way. Only the intestinal cells showed an increased IL-22 expression after $3 \mathrm{~h}$ of in vitro treatment with the bacteria.

\section{Discussion}

In the present study the characterization and expression of the two main Th-17 cytokines (IL17A and IL-22) have been studied in turbot. Both cytokines have a predicted signal peptide, suggesting that these molecules are secreted. Both the signal peptide and mature peptide were of similar sizes to the equivalent molecules in other fish species (Gunimaladevi et al. 2006; Monte et al., 2011). IL-17 protein multi-alignment revealed that the C-terminal region showed higher similarity to other fish and mammalian orthologs than the N-terminal region. Conservation of the Cterminal region was also seen amongst the human IL-17 genes (Aggarwal and Gurney; 2002). As in other fish species, turbot IL-17A/F possessed four conserved cysteines that are known to form two disulphide bridges (Gunimaladevi et al., 2006; Hymowitz et al., 2001). Moreover, three conserved serines (residues 83, 85 and 125) were apparent (Hymowitz et al., 2001). The presence of such conserved residues in turbot, as well as in species less related phylogenetically, suggests that these residues have an important role in the 3D structure.. Our 3D structural analysis predicted the presence of $\beta$-sheets in the IL-17 protein that are well conserved when compared with the human IL17 structure. The IL-22 protein multi-alignment revealed that the IL-10 family signature was relatively well conserved among all the analyzed species. Moreover, turbot IL-22 contains four cysteines, all of which are also conserved in other fish species, with three also conserved between mammals and fish. The presence of the same number of cysteines and the fact that human IL-22 
makes two disulphide bonds (Nagem et al., 2002), suggests that the turbot IL-22 cysteines may also form two inter-chain bridges. Moreover, the predicted 3D structure seems very similar to human IL22. The turbot IL-22 3'-UTR region has five ATTTA motifs, which are implicated in the stability of the mRNA, and are also common in IL-22 molecules from other fish species (Monte et al., 2011; Corripio-Miyar et al., 2009). A phylogenetic tree constructed with several molecules belonging to the IL-10 family revealed that turbot IL-22 grouped with other piscine IL-22 sequences and in a different clade to other IL-10 family members.

The tissue distribution expression in basal conditions showed the highest expression levels in the intestine followed by head kidney and gills. These results may indicate an important function of these Th-17 cytokines in mucosal associated immunity. Moreover, similar results were found in other fish species where these tissues are the main producers of IL-17 (Gunimaladevi et al., 2006) and IL22 (Monte et al., 2011), reinforcing a possible action at mucosal surfaces. Only a single study has looked at the biological activity of these molecules in fish to date (Monte et al., 2011) but their function in mucosal defenses has been well reported in mammalian species. In several human diseases such as inflammatory disorders of the intestine or mucosal-associated infections, the expression of IL-22 has been shown to be deregulated, suggesting a critical role in the maintenance of normal barrier homeostasis (Sonnenberg et al., 2011). In mammals, IL-22 is expressed by T cells, especially Th-17 and Th-22 subsets, $\gamma \delta$ T cells and in the novel NK subset NK22 cells (Sanos et al., 2009). In contrast, IL-22 receptor complex expression is restricted to cells with a non hematopoietic origin. This characteristic distribution allows immune cells to modulate responses in other cell types such as endothelial cells, fibroblasts, epithelial cells or different classes of cells present in the stromal tissue. Due to the high importance of the physical barriers as an innate defence and their important role in the promotion of antimicrobial immunity, the IL-22/IL-22R pathway appears to be critical in epithelial cells where the initiation and regulation of such responses occurs. However, IL-22 action has been shown to be a double-edged sword in processes such as infection, inflammation or autoimmunity showing pathologic or protective roles depending upon the context in which it is expressed (Sonnenberg et al., 2010). Our results showed significant increases in IL-22 expression after stimulation with the Gram-negative bacterium Aeromonas salmonicida. IL-22 modulation upon bacterial infection has also been reported in other fish species. For example, in rainbow trout, IL-22 expression was induced in spleen after stimulation with Yersinia ruckeri (Milena et al., 2011), whilst haddock vaccinated with formalin-killed Vibrio anguillarum had higher IL-22 expression levels than the controls after challenge with the same bacterium (Corripio-Miyar et al., 2009). In the current paper, we analyzed IL-22 expression following bacterial infection in two major immune organs (head kidney and spleen) and also in those tissues in which basal levels were high (intestine) or low 
(liver). Surprisingly, IL-22 expression was induced in head kidney, spleen and even in liver but not in the intestine. In mammals, studies have recently discovered the essential role of lymphotoxin in IL-22 production by intestinal lymphoid cells. Mice deficient in the lymphotoxin pathway show a decreased IL-22 production after bacterial infection (Tumanov et al., 2011). In fish, Komatsu et al. (2009) found that $A$. salmonicida is able to induce the expression of pro-inflammatory cytokines such as IL-1 $\beta$ or TNF $\alpha$ in intestinal cells but the same results were not found when the cells were treated with killed bacteria or with conditioned medium, suggesting the need for adhesion of the bacteria to the intestine surface. Such findings seem to indicate that an increase in IL-22 expression should have been expected in the turbot intestine after challenge with $A$. salmonicida but this was not the case. Perhaps the really high expression seen in normal conditions suggests the intestinal lymphoid cells can maintain IL-22 homeostasis at this site so as to avoid the potential for an unbalanced response that may switch between the protective and pathologic roles of this cytokine. Moreover, it is worth noting that the bacteria were injected into the visceral cavity in this study, thus lymphoid associated mucosal tissue was not exposed to the stimuli in the same manner as following orally administration.

The other Th-17 cytokine discovered in the current study, IL-17A/F, also showed highest expression in the intestine. IL-17 has not been described in many fish species to date but similar results have been found in some of them. In zebrafish and Fugu different isoforms of IL-17A/F have been described (Gunimaladevi et al., 2006; Korenaga et al., 2010). In Fugu, the expression of IL-17 A/F3 was detected in practically all tissues, whereas IL-17 A/F1 and F2 expression was mostly found in brain and head kidney. However, in zebrafish these isoforms are expressed mainly in the intestine (Kono et al., 2010). The different expression patterns could indicate a different role for each isoform. Despite the uncertainty about the biological function of each IL-17 isoform in fish, our results in general agree with mammalian data showing this cytokine plays a critical role in the maintenance of mucosal barrier function (Atarashi et al., 2010; Gaffen et al., 2011). In the present paper, IL-17 levels were positively modulated in spleen and head kidney after bacterial stimulation, but no significant differences were found in the liver and the intestine. The relation between intestinal pathogens and the IL-17 response has been widely studied in mammals, where this cytokine plays a central role in the inflammatory process and in antimicrobial defense. Geddes et al. (2011) showed that bacterial infection (with Citrobacter or Salmonella) provoked early IL-17 production which was mediated by a novel type of CD4+ T helper cell, enteric innate T helper type 17 (iT(H)17), which needs the presence of intestinal microbiota for the execution of the response. Likewise, Chen et al (2011) have recently demonstrated that memory Th-17 cells were able to proliferate in response to conserved membrane proteins and thus confer protection against several serotypes of the encapsulated bacteria, Klebsiella pneumoniae, in a typical model of mucosal immunization. These 
results suggest that IL-17 is able to confer protection through mucosal immunity and independent of a serotype-specific antibody response. Moreover, it has been shown that the accumulation of intestinal Th-17 cells depends on the concentration of intestinal commensal bacteria (Atarashi et al., 2010). Despite such findings our results did not show evidence of IL-17 modulation in the intestine after stimulation with A. salmonicida, as with IL-22 expression. The route of bacterial inoculation may explain the discrepancy between the present results for both Th-17 cytokines and the data widely reported in the bibliography as discussed above. With this in mind we are currently developing specific inflammation models where the role of IL-17 and IL-22 on mucosal associated immunity can be better studied.

The same bacterial stimulus (heat killed A. salmonicida) was used to stimulate in vitro culture cells from intestine, head kidney and spleen. In spite of differences were observed, only significant results were detected at $3 \mathrm{~h}$ in intestinal cells. The expression of both cytokines did not seem to be affected by the presence of the dead bacteria, suggesting that these Th-17 cytokines must not be involved in a direct defense against pathogens and that interaction with other cells must be needed as our in vivo experiments have suggested. However, evidence that IL-17A/F and IL-22 could be upregulated in intestinal cells, and hence potentially at this mucosal site was obtained in our in vitro experiments with PMA and PHA. Phorbol myristate acetate (PMA), is a potent enhancing factor for T cell colony growth (Allouche et al., 1990), and stimulation of total intestine leukocytes with PMA significantly increased expression of both cytokines at $3 \mathrm{~h}$ and $6 \mathrm{~h}$ post-stimulation, and at $24 \mathrm{~h}$ for IL17A/F. These data suggest that intestinal cells in contact with a pathogen or other stimuli may indeed be able to trigger signalling pathways that can induce a Th-17 type response. The production of Th17 cytokines (IL-17 and IL-22) upon PMA stimulation has also been found in other species. For example, in humans, PMA was able to induce CD4+ cell proliferation and increase IL-17 expression in patients with bronchoalveolar lavage fluid (BALF), making of this cytokine a good marker for specific pathologies in the lung, another mucosal rich tissue (De Luca et al., 2012). In fish, PMA also induced the expression of IL-22 in rainbow trout splenocyte primary cultures (Monte et al., 2011). We have showed that PMA induced the expression of both cytokines in the three analyzed tissues. Even when PHA was able to produce significant increases at some specific sampling points, the same effects were not observed. Both PMA and PHA are T cell inducers, but PMA is also a stimulator of intracellular signaling pathways. The stimulation of these signaling pathways could produce the indirect activation of IL-17 and IL-22 expression by means of other cytokines. Wang et al (2011) showed, in rainbow trout, the induction of IL-21 expression after the stimulation with PMA or PHA and the direct effect of recombinant IL-21 in IL-22 expression. Moreover, IL-17 and IL-22 are not only produced by $\mathrm{T}$ cells, suggesting that the activation of intracellular signals in other 
cellular types, such as NK-22 cells or neutrophils; B and CD8+ cells or also neutrophils could express IL-22 and IL-17 respectively.

In summary, we have sequenced the two main Th-17 cytokines and studied their expression in basal conditions and after stimulation both in vivo and in vitro. Despite some differences with data previously published in other species, our results indicate an important role of these novel cytokines in mucosal-associated immunity. Further studies are being conducted to determine the biological activity of these cytokines and to elucidate their role in inflammatory processes at mucosal surfaces, an area that has not yet been fully characterized in fish. Since turbot is a fish species with high economic importance to Spanish aquaculture, study of its mucosal associated immune system will likely help its production long term. 


\section{Acknowledgements}

This work was supported by the projects CSD2007-00002 "Aquagenomics" of the program Consolider-Ingenio 2010 and AGL2009-10677 from the Spanish Ministerio de Ciencia e Innovación. We want to thank Dr. M. L. Lemos (University of Santiago de Compostela, Spain) for the donation of Aeromonas salmonicida. Dr. Costa thanks the Consejo Superior de Investigaciones Científicas (CSIC, Spain) and the Xunta de Galicia for her “Ángeles Alvariño” postdoctoral contract. Ms Pereiro thanks the Ministerio de Educación for her FPU fellowship. 


\section{References}

Abraham, C., Medzhitov, R. 2011. Interactions between the host innate immune system and microbes in inflammatory bowel disease. Gastroenterology. 140, 1729-1737.

Aggarwal, S., Gurney, A.L., 2002. IL-17: prototype member of an emerging cytokine family. J. Leukoc. Biol. 71, 1-8.

Atarashi, K., Tanoue, T., Umesaki, Y., Honda, K., 2010. Regulation of Th17 cell differentiation by intestinal commensal bacteria. Benef. Microbes. 1, 327-334.

Campanella, J.J., Bitincka, L., Smalley, J., 2003. MatGAT: an application that generates similarity/identity matrices using protein or DNA sequences. BMC Bioinform. 4,29.

Cella, M., Fuchs, A., Vermi, W., Facchetti, F., Otero, K., Lennerz, J.K.M., Doherty, J.M., Mills, J.C., Colonna, M.. 2009. A human natural killer cell subset provides an innate source of IL-22 for mucosal immunity. Nature. 457, 722-725.

Chen, K., McAleer, J.P., Lin, Y., Paterson, D.L., Zheng, M., Alcorn, J.F., Weaver, C.T., Kolls, J.K. 2011. Th17 cells mediate clade-specific, serotype-independent mucosal immunity. Immunity. 35, 997-1009.

Chenna, R., Sugawara, H., Koike, T., Lopez, R., Gibson, T.J., Higgins, D.G., Thompson, J.D. 2003. Multiple sequence alignment with the Clustal series of programs. Nucleic. Acids. Res. 31, $3497-$ 3500 .

Corripio-Miyar, Y., Zou, J., Richmond, H., Secombes, C.J., 2009. Identification of interleukin-22 in gadoids and examination of its expression level in vaccinated fish. Mol. Immunol. 46, 2098-2106.

Davis, D.M., Dustin, M.L., 2004. What is the importance of the immunological synapse? Trends Immunol. 25, 323-327.

De Luca, A., Rindi, L., Celi, A., Melosini, L., Paggiaro, P., Nelli, L., Garzelli, C., Freer, G., 2012. Intracellular detection of interleukin 17 and other cytokines in human bronchoalveolar lavage fluid: A first assessment. Immunol, Lett. 141, 204-209.

Dumoutier, L., Louahed, J., Renauld, J.C., 2000. Cloning and characterization of IL-10-related T cell-derived inducible factor (IL-TIF), a novel cytokine structurally related to IL-10 and inducible by IL-9. J. Immunol. 164, 1814-1819.

Emanuelsson, O., Brunak, S., von Heijne, G., Nielsen, H., 2007. Locating proteins in the cell using TargetP, SignalP and related tools. Nat. Protoc. 2, 953-971.

Fonseca-Camarillo G, Mendivil-Rangel E, Furuzawa-Carballeda J, Yamamoto-Furusho JK. 2011. Interleukin 17 gene and protein expression are increased in patients with ulcerative colitis. Inflamm Bowel Dis.17: E135-6.

Fouser, L.A., Wright, J.F., Dunussi-Joannopoulos, K., Collins, M., 2008. Th17 cytokines and their emerging roles in inflammation and autoimmunity. Immunol. Rev. 226, 87-102. 
Gaffen, S.L., Kramer, J.M., Yu, J.J., Shen, F., 2006. The IL-17 cytokine family. Vitam. Horm. 74, $255-82$.

Gaffen, S.L., Hernández-Santos, N., Peterson, A.C., 2011. IL-17 signaling in host defense against Candida albicans. Immunol. Res. 50, 181-187.

Geddes, K., Rubino, S.J., Magalhaes, J.G., Streutker, C., Le Bourhis, L., Cho, J.H., Robertson, S.J., Kim, C.J., Kaul, R., Philpott, D.J., Girardin, S.E., 2011. Identification of an innate T helper type 17 response to intestinal bacterial pathogens. Nat. Med. 17, 837-844.

Ghoreschi, K., Laurence, A., Yang, X.P., Tato, C.M., McGeachy, M.J., Konkel, J.E., Ramos, H.L., Wei, L., Davidson, T.S., Bouladoux, N., Grainger, J.R., Chen, Q., Kanno, Y., Watford, W.T., Sun, H.W., Eberl, G., Shevach, E.M., Belkaid, Y., Cua, D.J., Chen, W., O'Shea, J.J., 2010. Generation of pathogenic $\mathrm{T}(\mathrm{H}) 17$ cells in the absence of TGF-beta signalling. Nature. 467, 967-971.

Gunimaladevi, I., Savan, R., Sakai, M., 2006. Identification, cloning and characterization of interleukin-17 and its family from zebrafish. Fish Shellfish Immunol. 21, 393-403.

Harrington, L.E., Hatton, R.D., Mangan, P.R., Turner, H., Murphy, T.L., Murphy, K.M., Weaver, C.T., 2005. Interleukin-17 producing CD4+ effector T cells develop via a lineage distinct from the $\mathrm{T}$ helper type 1 and 2 lineages. Nat. Immunol. 6, 1123-1132.

Harrington, L.E., Mangan, P.R.,Weaver, C.T., 2006. Expanding the effector CD4 T-cell repertoire: the Th17 lineage. Curr. Opin. Immunol. 18, 349-356.

Igawa, D., Sakai, M., Savan, R., 2006. An unexpected discovery of two interferon gammalike genes along with interleukin (IL)-22 and -26 from teleost: IL-22 and -26 genes have been described for the first time outside mammals. Mol. Immunol. 43, 999-1009.

Ishigame H, Kakuta S, Nagai T, Kadoki M, Nambu A, Komiyama Y, Fujikado N, Tanahashi Y, Akitsu A, Kotaki H, Sudo K, Nakae S, Sasakawa C, Iwakura Y. 2009. Differential roles of interleukin-17A and $-17 \mathrm{~F}$ in host defense against mucoepithelial bacterial infection and allergic responses. Immunity. 30:108-119.

Komatsu, K., Tsutsui, S., Hino, K., Araki, K., Yoshiura, Y., Yamamoto, A., Nakamura, O., Watanabe, T., 2009. Expression profiles of cytokines released in intestinal epithelial cells of the rainbow trout, Oncorhynchus mykiss, in response to bacterial infection. Dev. Comp. Immunol. 33, 499-506.

Kono, T., Korenaga, H., Sakai M., 2010. Genomics of fish IL-17 ligand and receptors: A review. Fish Shellfish Immunol. 31, 635-643.

Korenaga, H., Kono, T., Sakai, M., 2010. Isolation of seven IL-17 family genes from the Japanese pufferfish Takifugu rubripes. Fish Shellfish Immunol. 28, 809-818.

Kramer, J.M., Gaffen, S.L., 2007. Interleukin-17: a new paradigm in inflammation, autoimmunity, and therapy. J. Periodontol. 78:1083-93. 
Schmittgen TD, Livak KJ. 2008. Analyzing real-time PCR data by the comparative C(T) method. Nat Protoc. 2008;3(6):1101-8.

Maldonado, R.A., Irvine, D.J., Schreiber, R., Glimcher, L.H., 2004. A role for the immunological synapse in lineage commitment of CD4 lymphocytes. Nature. 431, 527-532.

Monte, M.M., Zou, J., Wang, T., Carrington, A., Secombes, C.J. 2011. Cloning, expression analysis and bioactivity studies of rainbow trout (Oncorhynchus mykiss) interleukin-22. Cytokine. 55, 62-73.

Mosmann,T.R., Coffman, R.L., 1989. TH1 and TH2cells: Different patterns of lymphokine secretion lead to different functional properties. Annu. Rev. Immunol. 7, 145-173.

Nagem, R.A., Colau, D., Dumoutier, L., Renauld, J.C., Ogata, C., Polikarpov, I., 2002. Crystal structure of recombinant human interleukin-22. Structure. 10, 1051-1062.

Ouyang, W., 2010. Distinct roles of IL-22 in human psoriasis and inflammatory bowel disease. Cytokine Growth Factor Rev. 21, 435-441.

Pieper, U., Webb, B.M., Barkan, D.T., Schneidman-Duhovny, D., Schlessinger, A., Braberg, H., Yang, Z., Meng, E.C., Pettersen, E.F., Huang, C.C., Datta, R.S., Sampathkumar, P., Madhusudhan, M.S., Sjölander, K., Ferrin, T.E., Burley, S.K., Sali, A., 2011. ModBase, a database of annotated comparative protein structure models, and associated resources. Nucleic Acids. Res. 39, D465-D474.

Roark, C.L., Simonian, P.L., Fontenot, A.P., Born, W.K., O’Brien, R.L. 2008. Gamma delta T cells: an important source of IL-17. Curr. Opin Immunol. 20, 353-357.

Roy, A., Kucukural, A., Zhang, Y., 2010. I-TASSER: a unified platform for automated protein structure and function prediction. Nat. Protoc. 5, 725-738.

Salinas, I., Meseguer, J., Esteban, M.A., 2007. Assessment of different protocols for the isolation and purification of gut associated lymphoid cells from the gilthead seabream (Sparus aurata L.). Biol Proced Online. 25; 43-55.

Sanos, S.L., Bui, V.L., Mortha, A., Oberle, K., Heners, C., Johner, C., Diefenbach, A., 2009. RORct and commensal microflora are required for the differentiation of mucosal interleukin 22-producing NKp46+ cells. Nat, Immunol. 10, 83-91.

Sonnenberg, G.F., Fouser, L.A., Artis, D., 2010. Functional biology of the IL-22-IL-22R pathway in regulating immunity and inflammation at barrier surfaces. Adv. Immunol. 107, 1-29.

Sonnenberg, G.F., Fouser, L.A., Artis, D., 2011. Border patrol: regulation of immunity, inflammation and tissue homeostasis at barrier surfaces by IL-22. Nat. Immunol. 12, 383-390.

Tamura, K., Peterson, D., Peterson, N., Stecher, G., Nei, M., Kumar, S., 2011. MEGA5: molecular evolutionary genetics analysis using maximum likelihood, evolutionary distance, and maximum parsimony methods. Molecular Biology and Evolution. doi:10.1093/molbev/msr121.

Tumanov, A.V., Koroleva, E.P., Guo, X., Wang, Y., Kruglov, A., Nedospasov, S., Fu, Y.X., 2011. Lymphotoxin controls the IL-22 protection pathway in gut innate lymphoid cells during mucosal pathogen challenge. Cell. Host. Microbe. 10, 44-53. 
Wang, T., Diaz-Rosales, P., Costa, M.M., Campbell, S., Snow, M., Collet, B., Martin, S.A., Secombes, C.J. 2011. Functional characterization of a nonmammalian IL-21: rainbow trout Oncorhynchus mykiss IL-21 upregulates the expression of the Th cell signature cytokines IFNgamma, IL-10, and IL-22. J Immunol. 186(2):708-721.

Wang, T., Secombes, CJ., 2003. Complete sequencing and expression of three complement components, $\mathrm{C} 1 \mathrm{r}, \mathrm{C} 4$ and $\mathrm{C} 1$ inhibitor, of the classical activation pathway of the complement system in rainbow trout Oncorhynchus mykiss. Immunogenetics. 55, 615-628.

Wolk, K., Kunz, S., Witte, E., Friedrich, M., Asadullah, K., Sabat, R., 2004. IL-22 increases the innate immunity of tissues. Immunity. 21, 241-254.

Wolk, K., Sabat, R., 2006. Interleukin-22: a novel T- and NK-cell derived cytokine that regulates the biology of tissue cells. Cytokine Growth Factor Rev. 17, 367-380.

Wolk, K., Witte, E., Wallace, E., Döcke, W.D., Kunz, S., Asadullah, K., Volk, H.D., Sterry, W., Sabat, R., 2006. IL-22 regulates the expression of genes responsible for antimicrobial defense, cellular differentiation, and mobility in keratinocytes: a potential role in psoriasis. Eur. J. Immunol. $36,1309-1323$.

Zenewicz, L.A., Flavell, R.A., 2011. Recent advances in IL-22 biology. Int Immunol. 23, 159-163.

Zhang, Y., 2007. Template-based modeling and free modeling by I-TASSER in CASP7. Proteins. 69, 108-117.

Zheng, Y., Valdez, P.A., Danilenko, D.M., Hu, Y., Sa, S.M., Gong, Q., Abbas, A.R., Modrusan, Z., Ghilardi, N., de Sauvage, F.J., Ouyang, W., 2008. Interleukin-22 mediates early host defense against attaching and effacing bacterial pathogens. Nat. Med. 14, 282-289.

Zou, J., Yoshiura, Y., Dijkstra, J.M., Sakai, M., Ototake, M., Secombes, C. 2004. Identification of an interferon gamma homologue in Fugu, Takifugu rubripes. Fish Shellfish Immunol 17, 403-409. 


\section{Figure legends:}

\section{Figure 1.}

Nucleotide (above) and deduced amino acid (below) sequence of the turbot IL-17A/F (A) and IL-22 (B) transcripts. The predicted signal peptide is highlighted in light grey. Start and stop codons for translation are boxed. The IL-10 family signature is highlighted in dark grey (B). The mRNA instability motifs (ATTTA) are underlined and the IL-22 polyadenylation signal (AATAAA) is in italics and underlined (B).

\section{Figure 2.}

Protein multiple alignment of selected IL-17 (A) and IL-22 (B) molecules. The predicted signal peptides are indicated above the involved amino acids. The conserved cysteines are indicated with a black rhombus $(\checkmark)$ and the predicted disulphide bonds, in comparison with the human molecules, are linked with lines. The conserved serines for IL-17A/F (A) are indicated with a hash (\#) and the IL-10 signature family for IL-22 (B) is grey boxed. The putative N-glycosylation sites for IL-17A and IL22 are clear boxed. The accession numbers of the sequences used for the alignment are: IL-17A halibut: EB039261.1; human: Q16552; mouse: Q62386; trout: Q70I21; IL-17A/F1 medaka: E3WEA7; zebrafish: Q5TKT4; IL-17A/F2 medaka: E3WEA8; zebrafish: Q5TKT3; IL-17A/F3 medaka: E3WEA9; zebrafish: Q5TKTO; IL-17F mouse: Q8K4C3; human: Q96PD4. IL-22: tilapia: XP_003448179; seabream: FG261948.1; trout: C5VUR1; cod: C0MHM0; haddock: B9ZSS4; mouse: Q9JJY9; human: Q9GZX6; cow: A5JS75.

\section{Figure 3.}

Predicted tertiary structure of turbot IL-17A/F and IL-22 compared with the human counterparts. (A) Turbot IL-17A/F and IL-22 tertiary structure. (B) Human IL-17A/F and IL-22 tertiary structure. (C) Comparison of the turbot and human IL-17 and IL-22 tridimensional structures. For human IL-17 are represented the different isoforms. Human isoform with the highest homology to turbot IL-17A/F is represented in blue and turbot IL-17 A/F is represented in green (C). For IL-22 alignment human is represented in grey and turbot IL-22 in green. The alignments were conducted using Modweb, ModBase and Pymol. The protein structure modelling was conducted using 3D-JIGSAW and ITASSER selecting the model with the best C-score.

\section{Figure 4.}

Unrooted phylogenetic trees of vertebrate IL-17 cytokine family members (A) and IL-10 cytokine family members (B). The trees were constructed using amino acid multiple alignments and the neighbour-joining method within the MEGA4 program (Tamura et al., 2007). Node values represent percent bootstrap confidence derived from 10,000 replicates. The evolutionary distances were computed using the JTT matrix-based method. All positions containing alignment gaps and missing data were eliminated only in pairwise sequence comparisons (Pairwise deletion option). The accession number for each sequence is given after the species name and molecular type. The turbot IL-17A/F and IL-22 molecules isolated in this study are highlighted in grey.

\section{Figure 5.}

Basal expression analysis of turbot IL-17A/F (A) and IL-22 (B) in heart, brain, muscle, liver, spleen, gills, head kidney and intestine obtained from healthy fish. The expression of transcripts was normalized to that of the housekeeping gene (EF-1 $\alpha)$ and expressed as arbitrary units, where 1 arbitrary unit was equal to the average expression level in heart for IL-17 and IL-22 respectively, which had the lowest expression level among the tissues studied. Data are represented as the mean + standard error $(n=5)$. 


\section{Figure 6.}

Expression analysis of turbot IL-17A/F and IL-22 in head kidney (HK), spleen, liver and intestine after an in vivo stimulation with the Gram negative bacterium Aeromonas salmonicida. The expression of IL-17 and IL-22 was normalized to the housekeeping gene EF-1 $\alpha$. Fold change was calculated by dividing the normalized expression values in the different samples by the normalized expression values obtained in the controls. Differences were considered statistically significant at $\mathrm{p}<0.05(*)$. Data are represented as the mean + standard error $(\mathrm{n}=5)$.

\section{Figure 7.}

Expression analysis of turbot IL-17A/F and IL-22 in head kidney (HK), spleen, and intestine cells after an in vitro stimulation with heat-killed Aeromonas salmonicida. The expression of IL-17 and IL-22 was normalized to the housekeeping gene EF-1 $\alpha$. Fold change was calculated by dividing the normalized expression values in the different samples by the normalized expression values obtained in the controls. Differences were considered statistically significant at $\mathrm{p}<0.05$ (*). Data are represented as the mean + standard error $(n=5)$.

\section{Figure 8.}

Expression analysis of turbot IL-17A/F and IL-22 in head kidney (HK), spleen, and intestine cells after an in vitro stimulation with PMA (dark grey) or PHA (light grey). The expression of IL-17A/F and IL-22 genes was normalized to the housekeeping gene EF-1 $\alpha$. Fold change was calculated by dividing the normalized expression values in the different samples by the normalized expression values obtained in the controls. Differences were considered statistically significant at $\mathrm{p}<0.05$ $(*)$. Data are represented as the mean + standard error $(n=5)$. 
Table 1A.

Primers used for IL-17A/F cloning, RACE, amplification and real time PCR (qPCR).

\begin{tabular}{|c|c|c|}
\hline Name & Sequence (5' to 3') & Application \\
\hline IL-17-TotalF1 & ACGACGACCTGCGACTTTAC & Amplification of complete ORF \\
\hline IL-17-TotalR1 & GCTGCTCTTCACTGTTGCTG & Amplification of complete ORF \\
\hline Turbot-IL-17-5'Race & AACGGTCCCCTGCAGCTGG & 5' Race \\
\hline Turbot-IL-17-3'Race & AGCTACATCTACAGGCTGGAGTCCCG & 3' Race \\
\hline T3-F2 & AAYGGTCCCCTGCAGCTGG & Cloning \\
\hline T3-gwR2 & ACCACAAACATCATACCGCTCGAG & Cloning \\
\hline T3-gwR1 & CTCCCACGACGACGATCTCTTCC & Cloning \\
\hline T3-gwF1 & AGGCTCGCTGTCTGCTGAAG & Cloning \\
\hline T3-gwF2 & GCGGGGCACAGCTACATCTACAG & Cloning \\
\hline T3-R2 & GTGGGCTGCACCTGCGTCC & Cloning \\
\hline IL-17-qPCR-F1 & GGGGCACAGCTACATCTACA & qPCR \\
\hline IL-17-qPCR-R1 & TACGGAAGACCAGTGATGTCA & qPCR \\
\hline
\end{tabular}

Table $1 \mathrm{~B}$.

Primers used for IL-22 cloning, RACE, amplification and real time PCR (qPCR).

\begin{tabular}{|c|c|c|}
\hline Primer & Sequence (5' to 3') & Application \\
\hline IL-22Total-F1 & TTCTGTCTCCCGACTTTCTGA & Amplification of complete ORF \\
\hline IL-22Total-R1 & TGTCGTGGATGTGATGAAAAA & Amplification of complete ORF \\
\hline IL-22-5' Race & AGATCTGCTGCCTGCACGCCA & 5' Race \\
\hline T5-F1 & AGATCTGCTGCCTGCACGCCA & Cloning \\
\hline T5-R2 & TCGCTGATTGCTTTGGTGATGCC & Cloning \\
\hline IL-22-qPCR-F2 & GCTGCAGCGTGACTCACTA & qPCR \\
\hline IL-22-qPCR-R2 & CTGCAGGTACGTGAAGAGGA & qPCR \\
\hline
\end{tabular}


Table 2.

Amino acid identities (top right) and similarities (bottom left) of turbot IL-17A/F to mammalian IL17A and $\mathrm{F}$ and fish IL-17A/F1, A/F2 and A/F3. The accession numbers of the protein sequences are the same as in Fig. 4. The similarities/identities to fish IL-17A/F1 are highlighted.

\begin{tabular}{|c|c|c|c|c|c|c|c|c|c|c|c|c|c|c|c|}
\hline & & \multirow[b]{2}{*}{2} & \multicolumn{2}{|c|}{ IL-17A } & \multicolumn{2}{|c|}{ IL-17F } & \multicolumn{3}{|c|}{ Fish IL-17A1 } & \multicolumn{3}{|c|}{ Fish IL-17A2 } & \multicolumn{3}{|c|}{ Fish IL-17A3 } \\
\hline & & & 3 & 4 & 5 & 6 & 7 & 8 & 9 & 10 & 11 & 12 & 13 & 14 & 15 \\
\hline 1. Turbot-IL-17A & & 60.8 & 29.0 & 28.0 & 27.0 & 30.5 & 32.6 & 55.8 & 56.9 & 19.8 & 23.7 & 23.1 & 32.4 & 29.0 & 29.3 \\
\hline 2. Halibot-IL-17A & 72.5 & & 27.6 & 26.3 & 26.0 & 26.6 & 39.3 & 54.2 & 55.0 & 22.4 & 23.3 & 22.4 & 32.9 & 26.0 & 28.0 \\
\hline 3. Human-IL-17A & 48.5 & 48.1 & & 62.0 & 47.2 & 50.3 & 30.0 & 30.5 & 25.3 & 33.8 & 31.4 & 30.7 & 32.7 & 30.1 & 32.0 \\
\hline 4. Mouse-IL-17A & 50.9 & 49.4 & 74.7 & & 38.3 & 45.2 & 25.8 & 28.0 & 26.3 & 32.7 & 27.5 & 29.8 & 31.5 & 26.3 & 28.4 \\
\hline 5. Human-IL-17F & 47.4 & 51.9 & 63.9 & 59.5 & & 57.5 & 27.2 & 29.2 & 30.0 & 29.8 & 33.1 & 28.7 & 30.1 & 32.1 & 31.5 \\
\hline 6. Mouse-IL-17F & 50.3 & 49.4 & 64.5 & 63.9 & 76.5 & & 33.5 & 37.2 & 32.4 & 32.1 & 27.8 & 31.4 & 34.1 & 32.3 & 32.7 \\
\hline 7.Zebrafish-IL-17A1 & 53.8 & 58.1 & 48.4 & 43.7 & 52.3 & 50.3 & & 34.8 & 37.7 & 25.3 & 26.1 & 28.5 & 33.1 & 31.6 & 35.7 \\
\hline 8. Fugu-IL-17A1 & 67.3 & 71.3 & 50.6 & 52.5 & 54.4 & 55.6 & 52.5 & & 51.7 & 21.1 & 24.5 & 25.8 & 35.1 & 32.4 & 31.4 \\
\hline 9. Medaka-IL-17A1 & 66.7 & 71.3 & 45.8 & 44.9 & 52.3 & 50.3 & 57.5 & 68.8 & & 21.4 & 23.1 & 26.6 & 34.5 & 31.7 & 33.1 \\
\hline 10. Zebrafish-IL-17A2 & 36.3 & 36.3 & 45.8 & 45.6 & 47.7 & 49.0 & 43.8 & 35.6 & 36.2 & & 35.6 & 36.6 & 27.7 & 29.7 & 29.0 \\
\hline 11. Fugu-IL-17A2 & 36.3 & 40.6 & 46.5 & 46.8 & 50.3 & 44.4 & 48.4 & 42.5 & 42.1 & 53.5 & & 55.6 & 29.1 & 28.6 & 26.9 \\
\hline 12. Medaka-IL-17A2 & 35.7 & 36.3 & 43.2 & 44.3 & 46.4 & 46.4 & 43.8 & 40.0 & 42.1 & 54.2 & 68.1 & & 27.4 & 23.0 & 26.5 \\
\hline 13. Zebrafish-IL-17A3 & 50.9 & $\mathbf{5 7 . 4}$ & 46.9 & 45.7 & 46.3 & 45.7 & 52.5 & 56.8 & 54.3 & 40.7 & 44.4 & 38.9 & & 40.0 & 39.1 \\
\hline 14. Fugu-IL-17A3 & 50.3 & 55.6 & 46.8 & 44.9 & 52.5 & 50.6 & 48.1 & 53.8 & 53.2 & 39.9 & 44.9 & 43.0 & 53.1 & & 50.6 \\
\hline 15. Medaka-IL-17A3 & 52.0 & 55.0 & 49.0 & 46.2 & 49.7 & 47.8 & 54.1 & 54.4 & 52.9 & 42.7 & 42.0 & 40.8 & 56.2 & 67.1 & \\
\hline
\end{tabular}


Table 3.

Amino acid identities (top right) and similarities (bottom left) of turbot IL-22 to mammalian and fish IL-22. The accession numbers of the protein sequences are the same as in Fig. 4. The similarities/identities to fish IL-22 are highlighted.

\begin{tabular}{|l|c|c|c|c|c|c|c|c|}
\cline { 2 - 9 } \multicolumn{1}{c|}{} & \multicolumn{10}{c|}{ IL-22 } \\
\hline & 1 & 2 & 3 & 4 & 5 & 6 & 7 & 8 \\
\hline 1. IL-22-Trout & & 39.8 & 41.8 & 42.9 & 46.3 & 24.2 & 26.9 & 23.6 \\
\hline 2. IL-22-Tilapia & 61.2 & & 44.5 & 43.5 & 54.2 & 25.0 & 23.7 & 21.9 \\
\hline 3. IL-22-Cod & 62.4 & 61.7 & & 88.3 & 48.2 & 26.3 & 27.8 & 26.5 \\
\hline 4. IL-22-Haddock & 61.8 & 60.1 & 92.0 & & 48.2 & 26.5 & 28.1 & 27.3 \\
\hline 5. IL-22-Turbot & 67.4 & 71.3 & 63.1 & 62.6 & & 26.4 & 25.7 & 25.4 \\
\hline 6. IL-22-Mouse & 48.6 & 50.5 & 48.0 & 46.9 & 48.7 & & 78.2 & 56.8 \\
\hline 7. IL-22-Human & 50.3 & 46.3 & 46.4 & 46.9 & 50.8 & 89.4 & & 65.3 \\
\hline 8. IL-22-Cow & 45.8 & 45.8 & 44.2 & 44.7 & 46.8 & 73.7 & 80.0 & \\
\hline
\end{tabular}


TGACGACGACCTGCGACTT TACAACGAT TCAATCAGTCAGAGACGAATACTGT CGAACCTGCACCT CCAGCCGAGCCCEGGGAACCTTCG

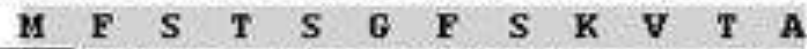
CACTGCTGACA TCATCTGCT CAAAGAAT CTGAAGAAGACGACGGCGAAT TCAAAATGTTT TAACATCAGGCT TCTCCAAAGTGACGGCT

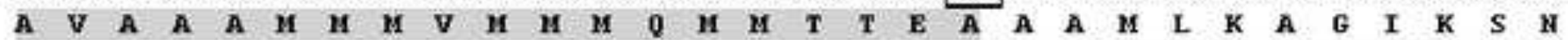
GCCGTTGCGGCGGCGATGATGATGGTGATGATGATGCAGAT GATGACGACGGAGGCGGCGGCCATGTTGAAAGCAGGCATCAAATCAAAT

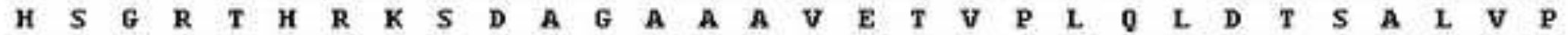
CACTCAGGGAGGACACACAGGAAGTCTGACGCCGGCGCCGCCGCGGTAGAAACGGTCCCCCTGCAGCTGGACACCAGCGCTTTGGTTCCT $\begin{array}{llllllllllllllllllllllllllllllll} & \mathbf{T} & \mathbf{T} & \mathbf{H} & \mathbf{I} & \mathbf{I} & \mathbf{P} & \mathbf{L} & \mathbf{E} & \mathbf{H} & \mathbf{S} & \mathbf{S} & \mathbf{I} & \mathbf{S} & \mathbf{P} & \mathbf{W} & \mathbf{T} & \mathbf{Y} & \mathbf{V} & \mathbf{V} & \mathbf{S} & \mathbf{H} & \mathbf{D} & \mathbf{D} & \mathbf{D} & \mathbf{L} & \mathbf{F} & \mathbf{P} & \mathbf{R} & \mathbf{I} & \mathbf{L}\end{array}$ ACCACAAACATCATACCGCTCGAGAACTCCTCCATCTCGCCGTGGACGTACAACGTCTCCCACGACGACGATCTCTTCCCCCGGATCCTG

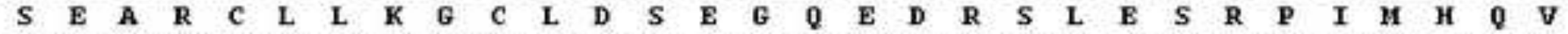
TCGGAGGCTCGCTGTCTGCTGAAGGGCTGCCTGGACTCCGAGGGCCAGGAGGACCGCAGCCTGGAGTCCAGGCCCATAATGCACCAGGTG $\begin{array}{lllllllllllllllllllllllllllllll}\mathbf{L} & \mathbf{L} & \mathbf{L} & \mathbf{R} & \mathbf{R} & \mathbf{F} & \mathbf{K} & \mathbf{P} & \mathbf{A} & \mathbf{R} & \mathbf{A} & \mathbf{G} & \mathbf{H} & \mathbf{S} & \mathbf{Y} & \mathbf{I} & \mathbf{X} & \mathbf{R} & \mathbf{L} & \mathbf{E} & \mathbf{S} & \mathbf{R} & \mathbf{L} & \mathbf{A} & \mathbf{A} & \mathbf{V} & \mathbf{G} & \mathbf{C} & \mathbf{T} & \mathbf{C}\end{array}$ CTGCTGCTGCGGCGGTTCAAGCCGGCGAGGGCGGGCACAGCTACATCTACAGGCTGGAGTCCCGCCTCATGGCGGTGGGCTGCACCTGC $\begin{array}{llllllllllllll}\mathbf{V} & \mathbf{R} & \mathbf{H} & \mathrm{I} & \mathrm{V} & \mathbf{0} & \mathbf{0} & \mathbf{0} & \mathbf{0} & -\end{array}$

GTCCGACACATAGTGCAACAGCAACAGTGARGAgCAGCA

AGGT TAAAAAAACTTCTGTCTCCCGACT TTCTGATCTCACTCGTTCAACCGTCCACAGAGATGAAGC TCCACGTT TCCACGGTGACACCA

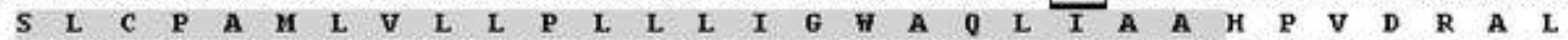
TCCCTCTGTCCAGCGATGCTCGTCCTGCTGCCGCTGCTCCTGATTGGCTGGGCCCAGCTGATCGCAGCGCACCCTGTGGACCGGGCGCTC $\begin{array}{lllllllllllllllllllllllllllllll}\mathbf{S} & \mathbf{H} & \mathbf{P} & \mathbf{L} & \mathbf{R} & \mathbf{S} & \mathbf{P} & \mathbf{D} & \mathbf{T} & \mathbf{Y} & \mathbf{Q} & \mathbf{A} & \mathbf{V} & \mathbf{R} & \mathbf{E} & \mathbf{V} & \mathbf{S} & \mathbf{0} & \mathbf{H} & \mathbf{A} & \mathbf{0} & \mathrm{T} & \mathbf{S} & \mathbf{L} & \mathbf{T} & \mathbf{E} & \mathbf{D} & \mathbf{D} & \mathbf{S} & \mathbf{S}\end{array}$ AGCCACCCGCTGCGGAGCCCCGACACGTACCAGGCCGTCCGGGAAGTGTCGCAGCACGCT CAGACTTCACTGACGGAGGACGACTCCAGC

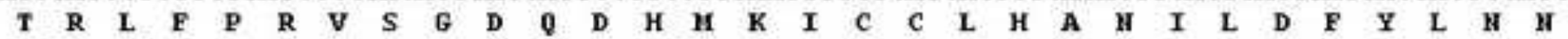
ACCAGACTGTTTCCTCGGGTCAGCGGTGACCAGGACCACATGAAGATCTGCTGCCTCCACGCCAACATCCTGGACTTCTACCTGAACAAC

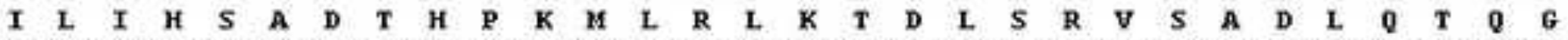
ATCCTGATTCACAGCGCCGACACGCATCCCAAGATGCTCCGGCTGAAGACCGACCTGTCCCGCGTCAGCGCCGACCTGCAGACTCAAGGC

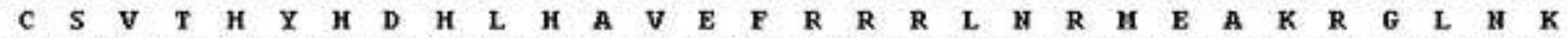
TGCAGCGT GACT CACTATCACGAT CATCTTCACGCCGTGGAGTTT CGCCGGAGACT CAACAGGATGGAGGCCAAGCGAGGTCTGAACAAA

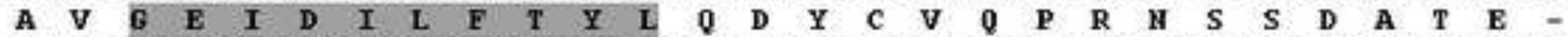
GCCGTGGGAGAGATCGACAT CCTCTTCACGTACCTGCAGGATTACTGCGTCCAGCCGAGAAACTCCAGCGACGCCACCGAGTGACGCCTC CACTGTTT CTTCTGAACTATT TATATTTATCAGCTT TATACATC CACTTTT TATACTTTAAGT TATTCATC TATT TAATATGAGAAACA TATT TAAAAAGTTTTTTTAAAATA TAAATATTTATTAAAACTCGGTTGCGACAGTTTTAGTTGTTGATCTGTTTATTGATCAGAATGTTT GGATACCGGAGCTGAAGGATCCCGGTGTCGACCACGTTGCCATGTTCATGGCGGAT TATTAGTT T TAT TACAGTTT TAAAAGAAATGTCT TGTTACATGTCGTGGATGTGATGAAAAAAATACATGTAAA CCCATTTTTTACTTGAATAAATAAAGTT TGGT TCAAATAAGAAAAAAAAA ARAAAAAAAAAA 
A

2L-17x-turbet IL-17A-Failisut IL-17A/ri-2ebratias

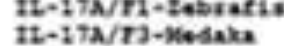
IL-17A/R-Medaia

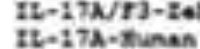

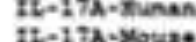

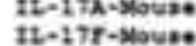

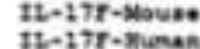
II-17 $\lambda$-Trees IL-17N/rit-Hedex. IL-17N/rit-tabratial consensus:

IL-12h-Turbot II-17k-Faliavs IL-17N/rI-3tedaks IL-17N/ri-Eebratis: II-172/r3-Madaks IL-17N/T3-tebrafiak rt-17a-minam tz-17x-4lowes.

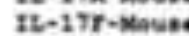
TL-17r-Muman It-17N/ri-Masex. it-17x/riz-zebrafiah esnsenswa
Sienal peptide
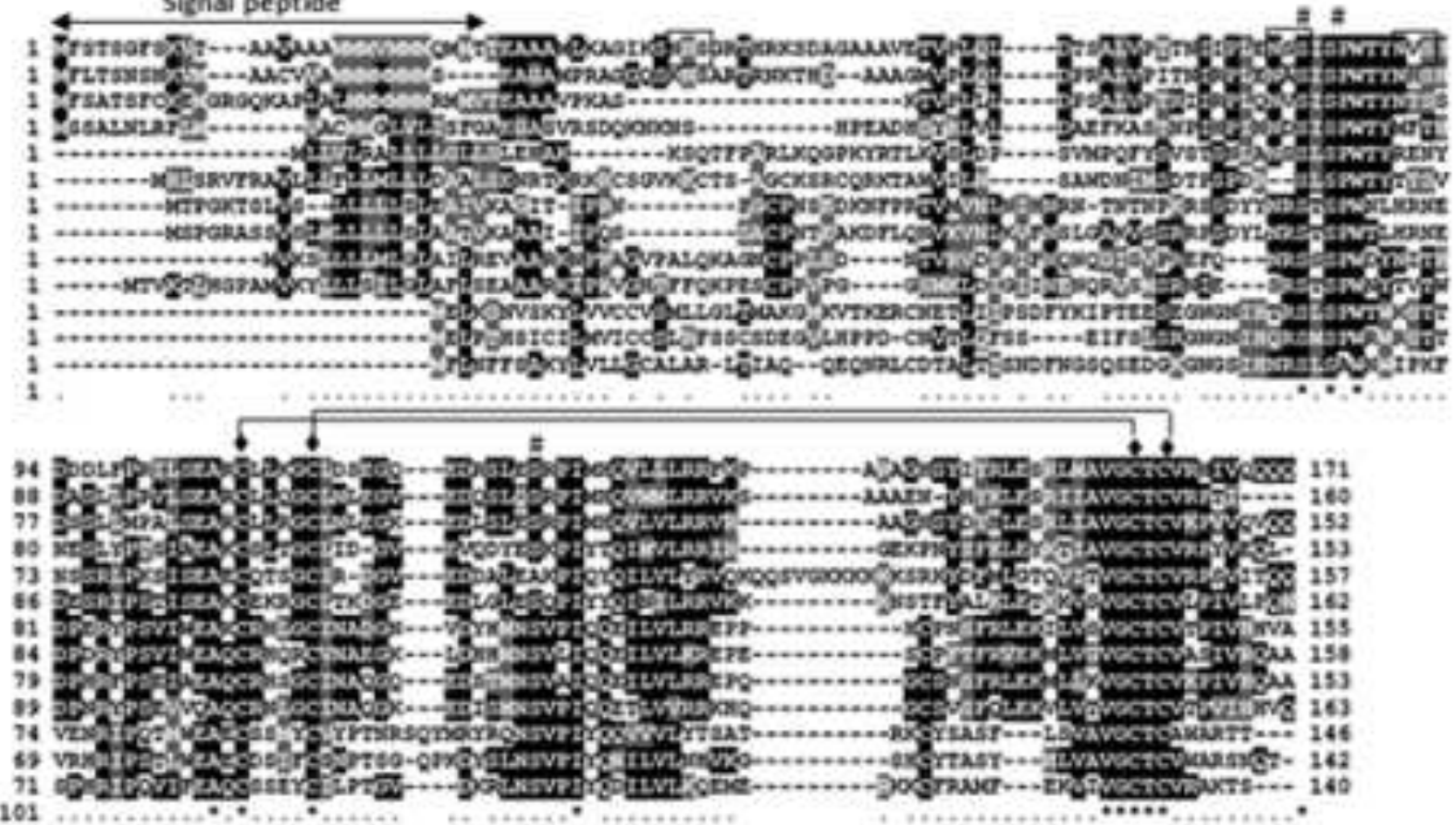

B

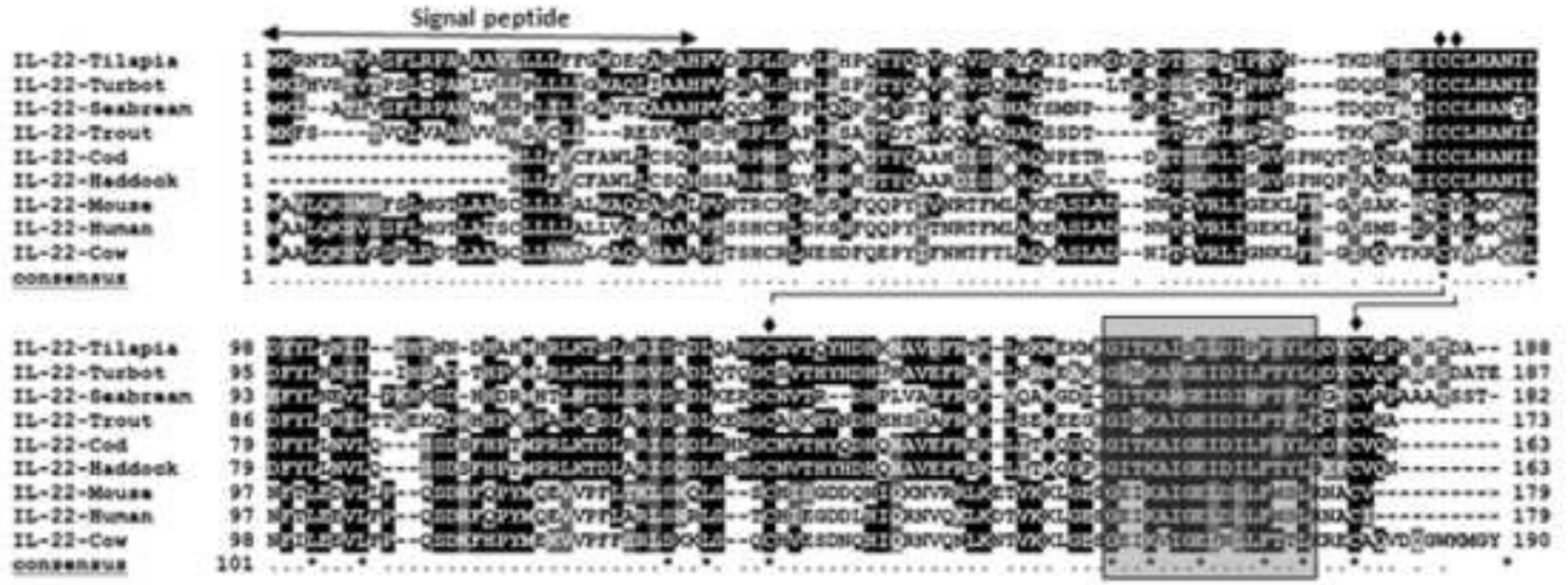


Click here to download high resolution image

$$
\text { IL-17A }
$$

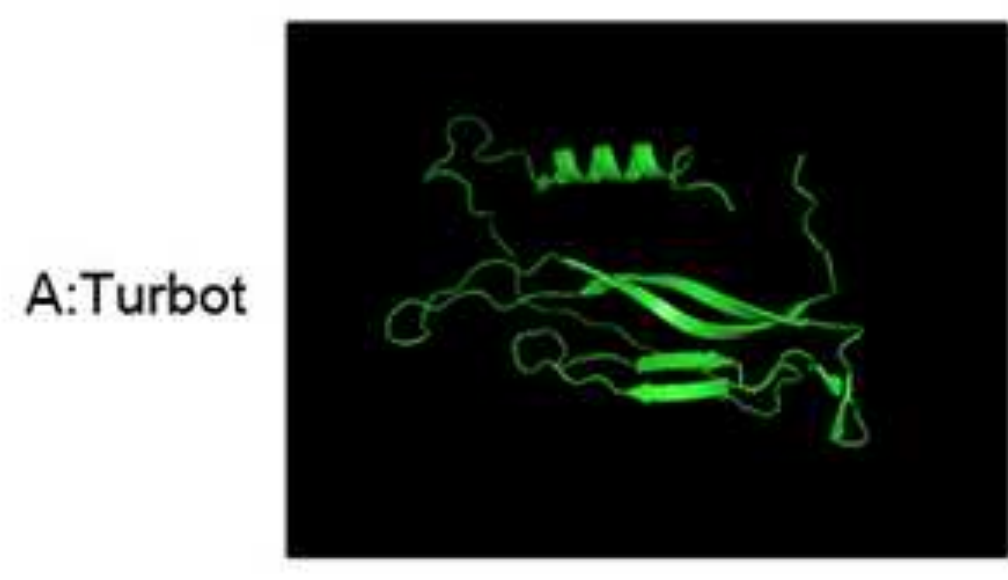

B: Human

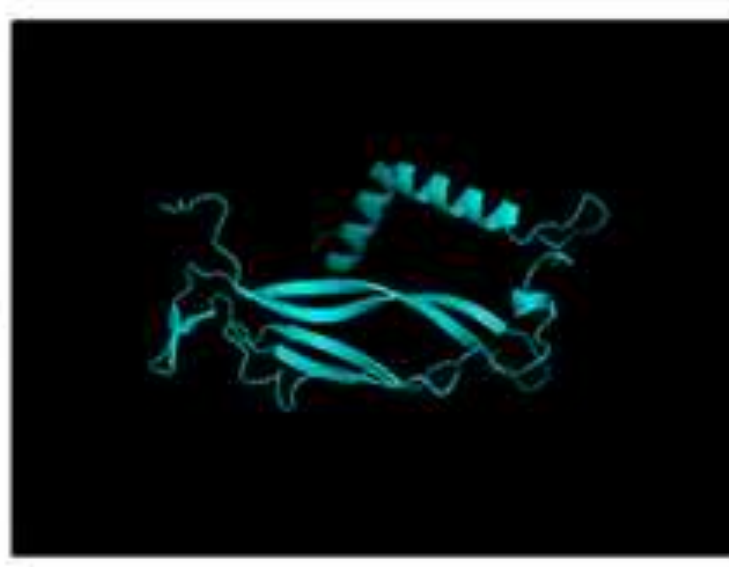

C: Turbot $+$ Human
IL-22
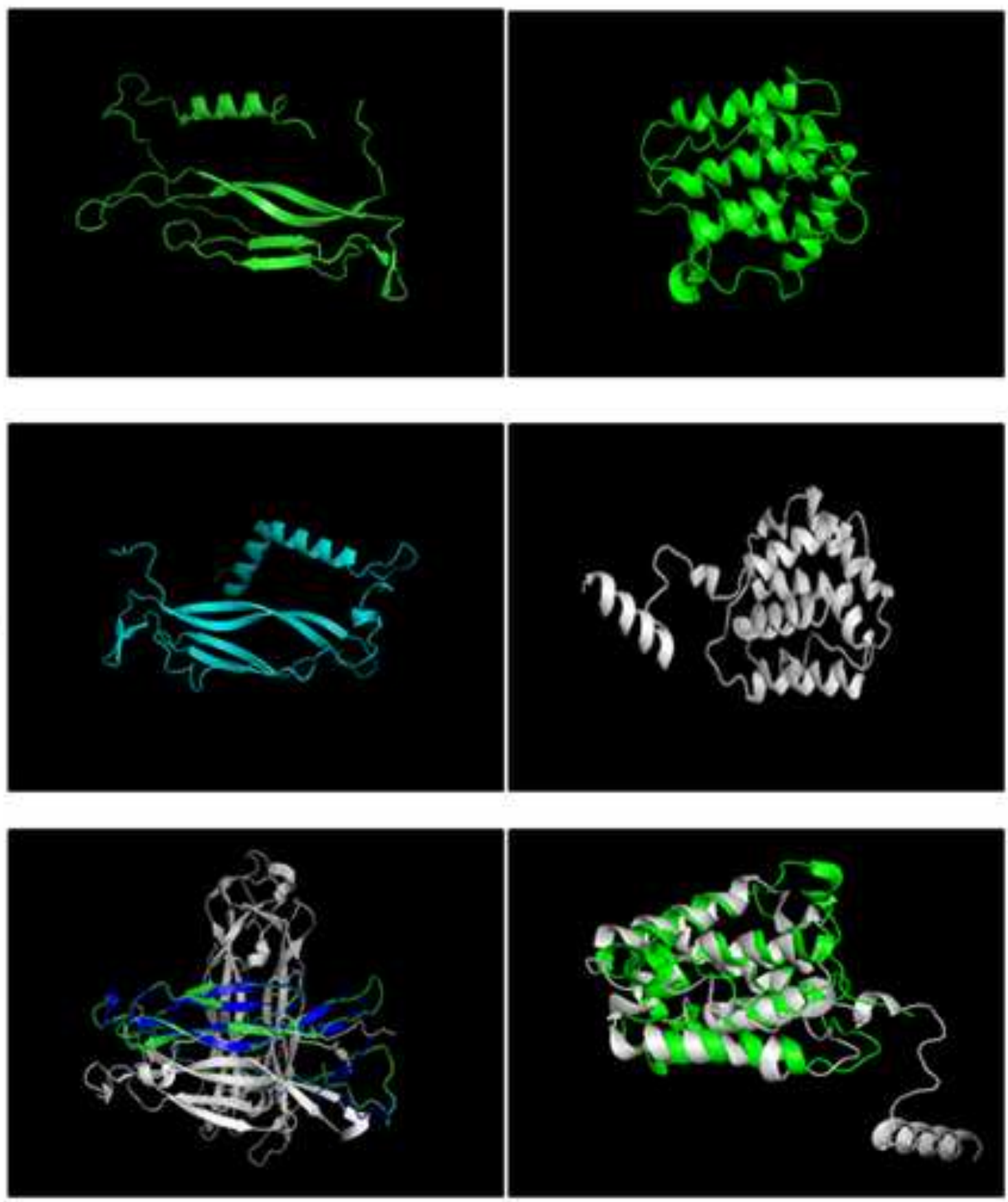

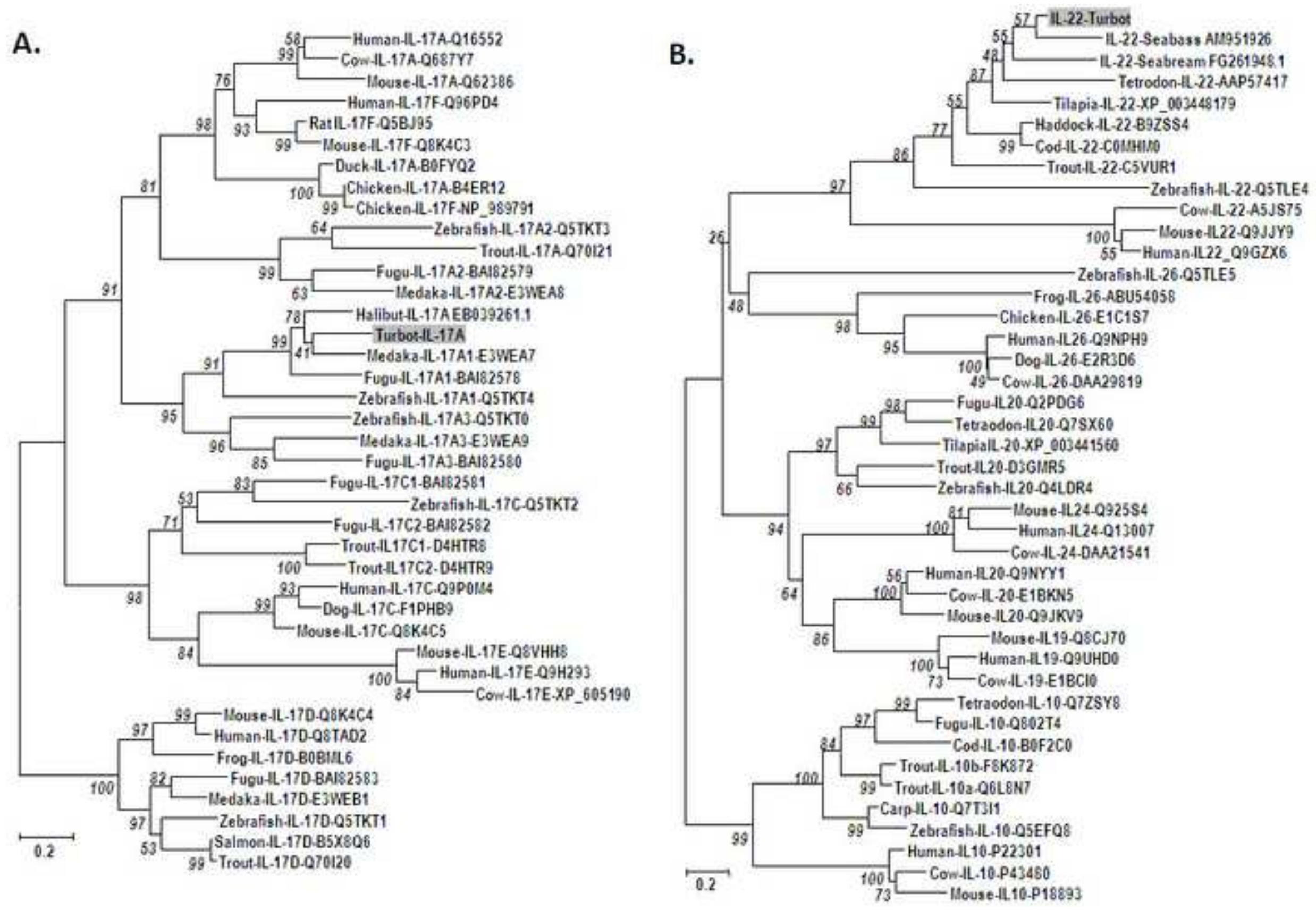
Click here to download high resolution image

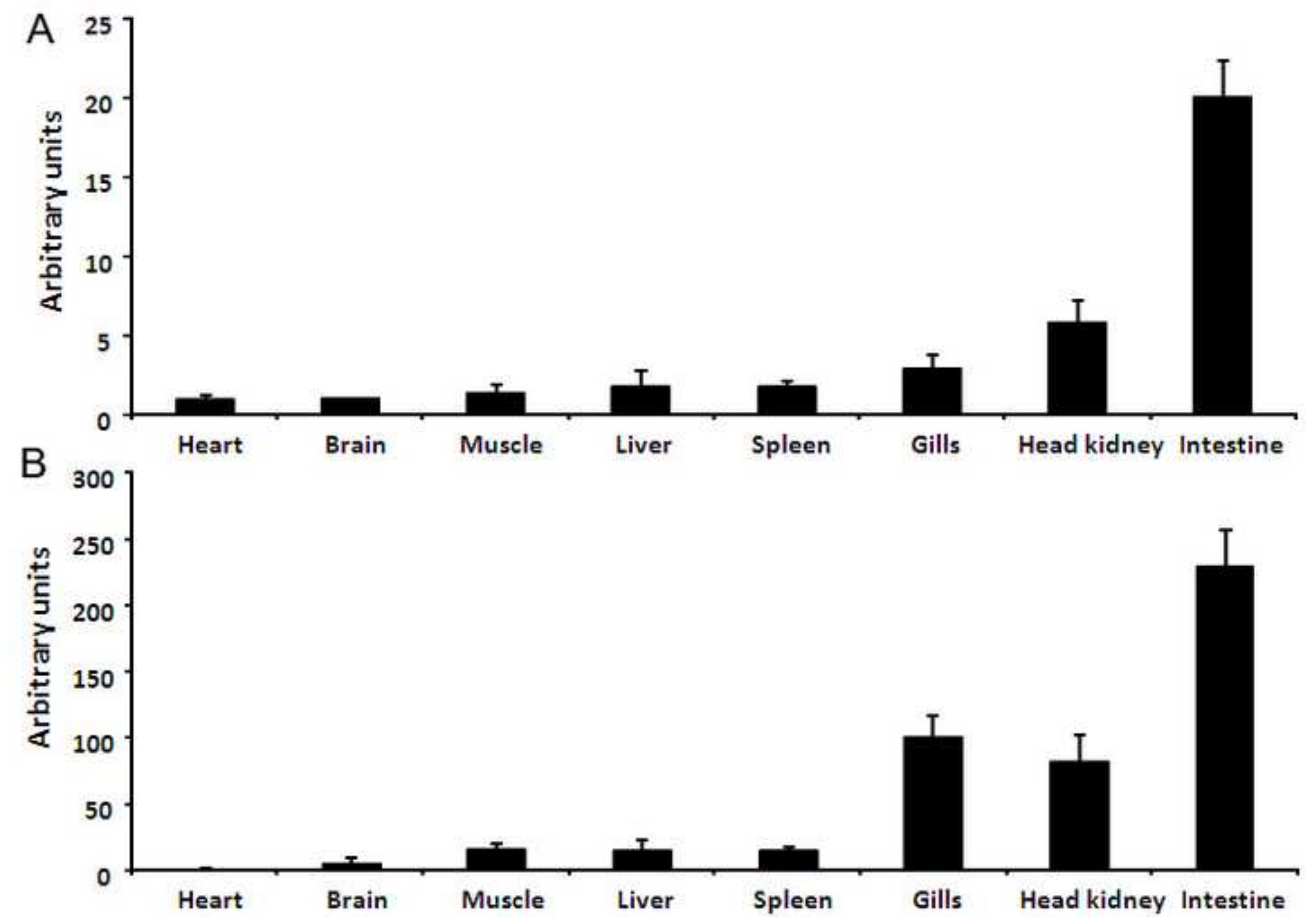

Click here to download high resolution image 
HK

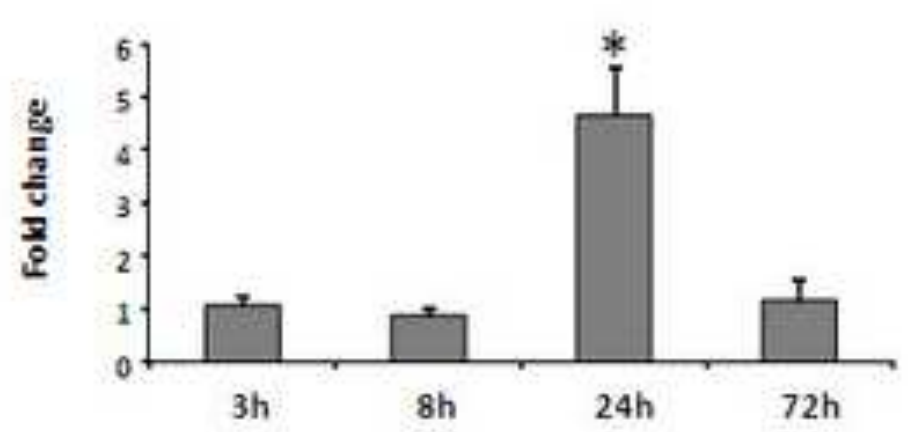

Spleen

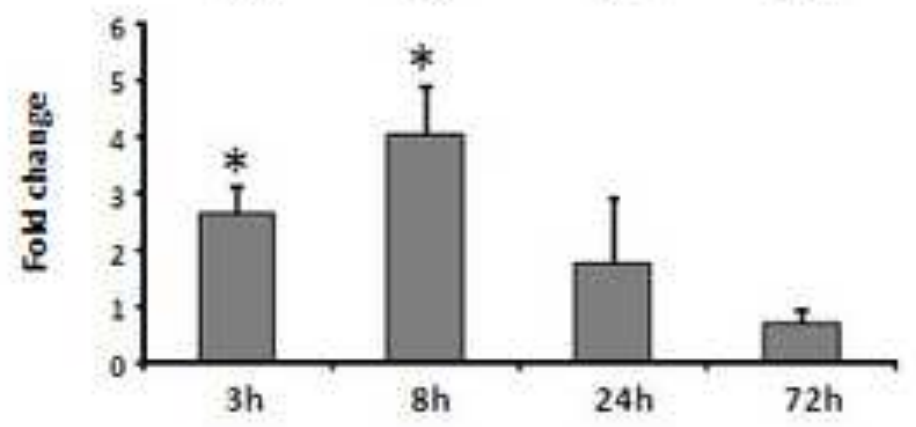

Liver

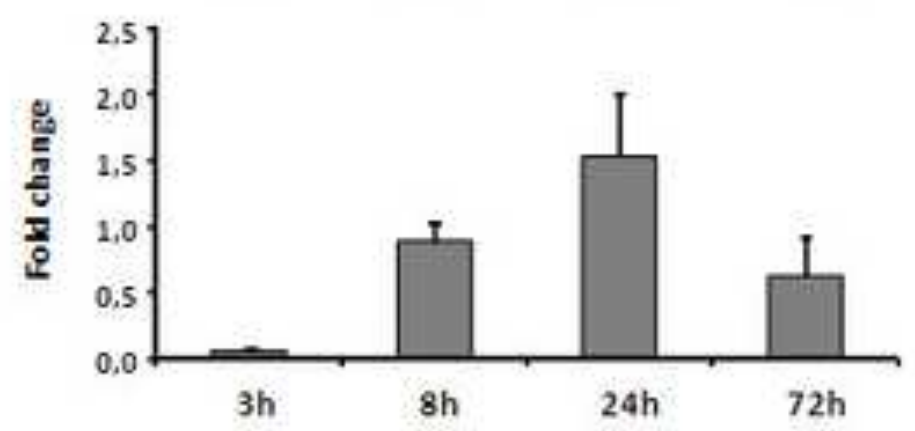

Intestine

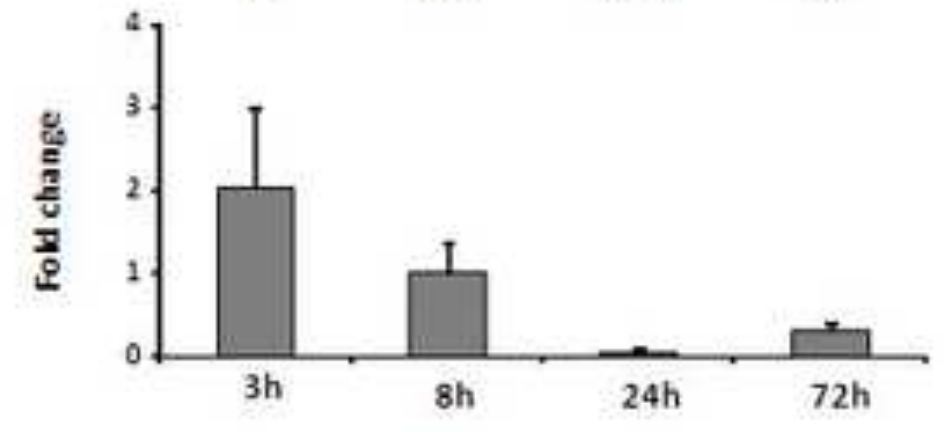

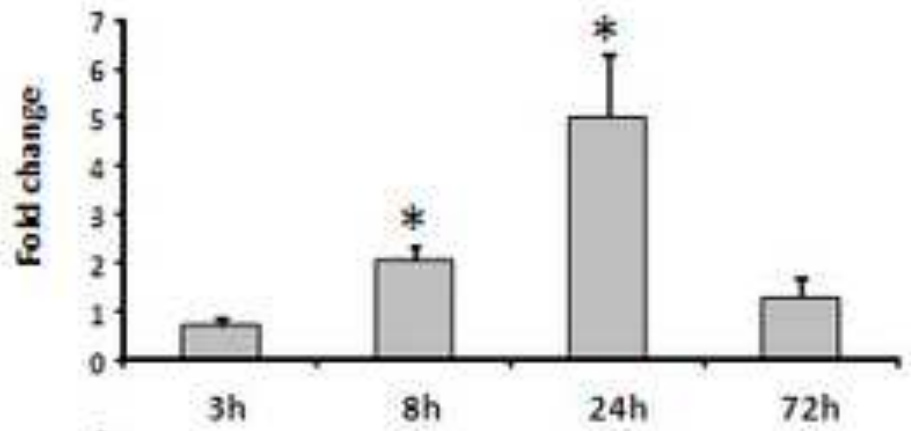
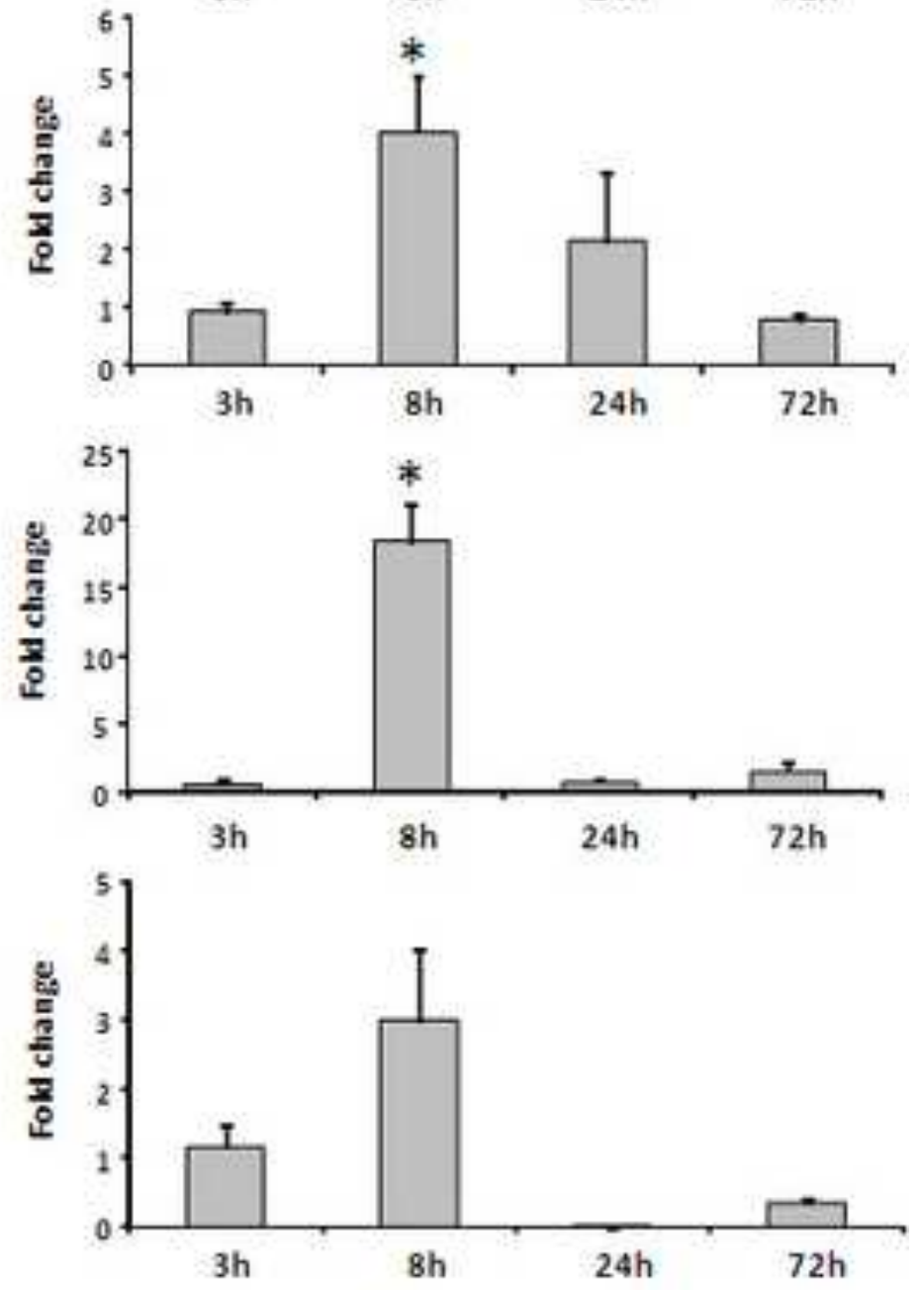
Click here to download high resolution image
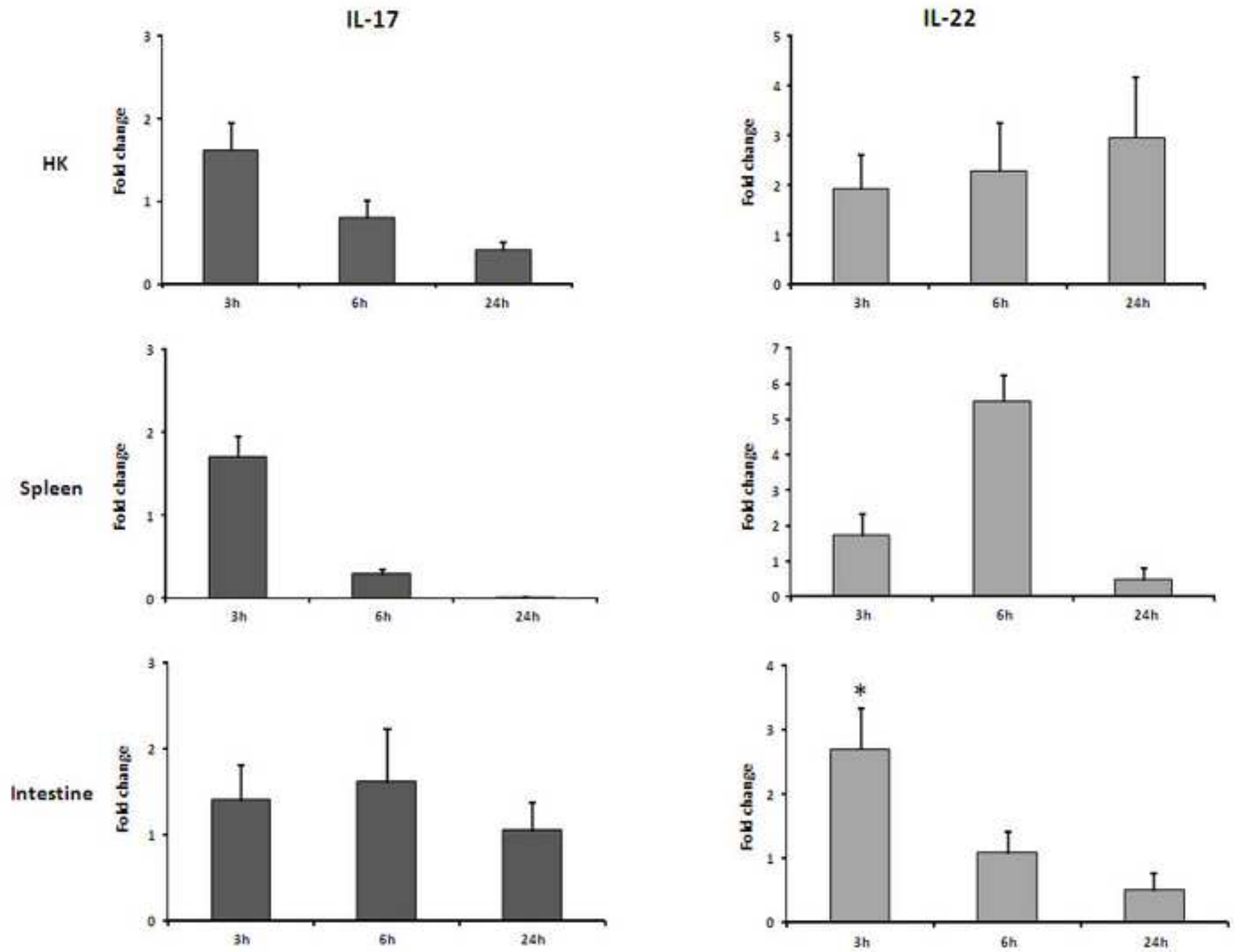
IL-17
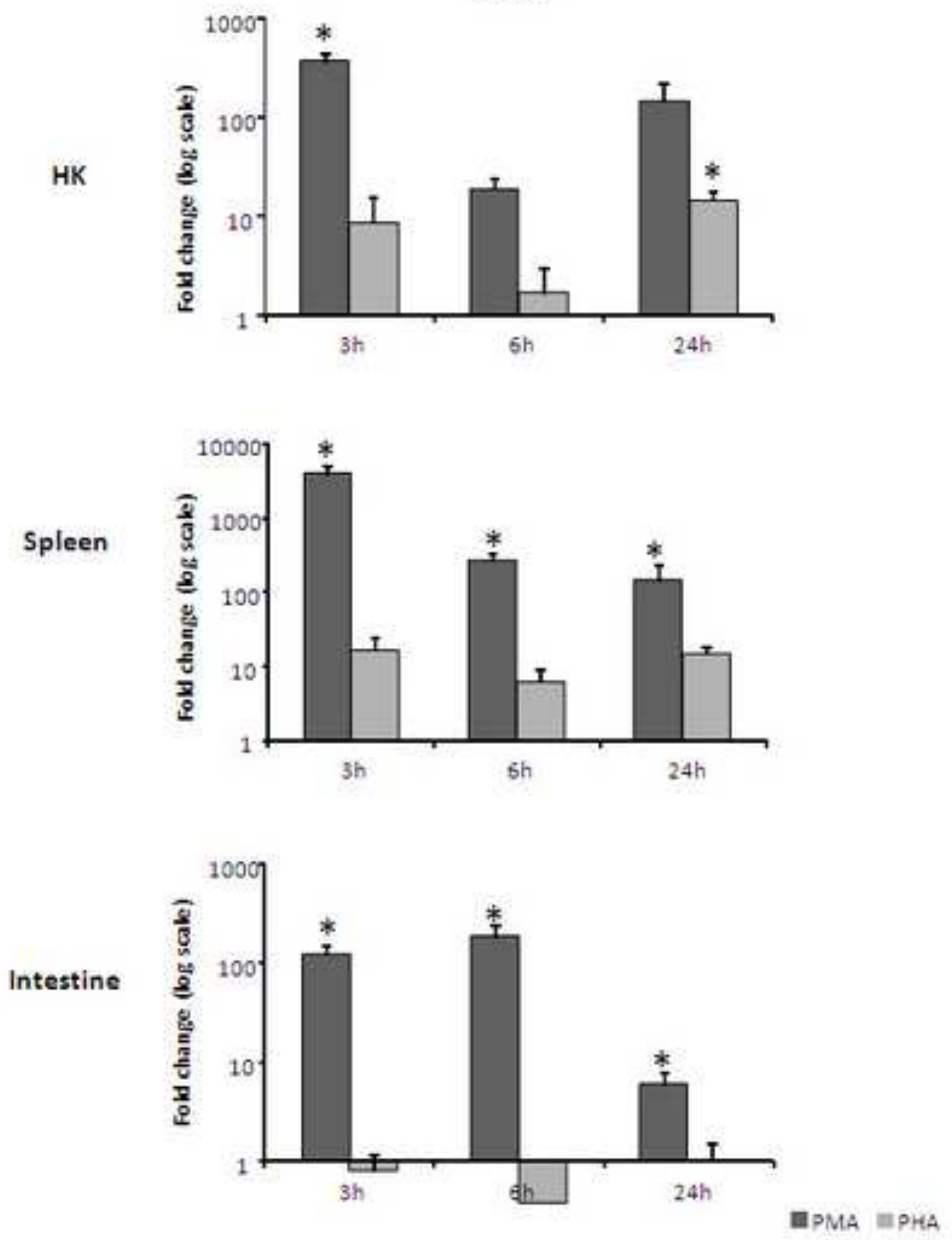

IL-22
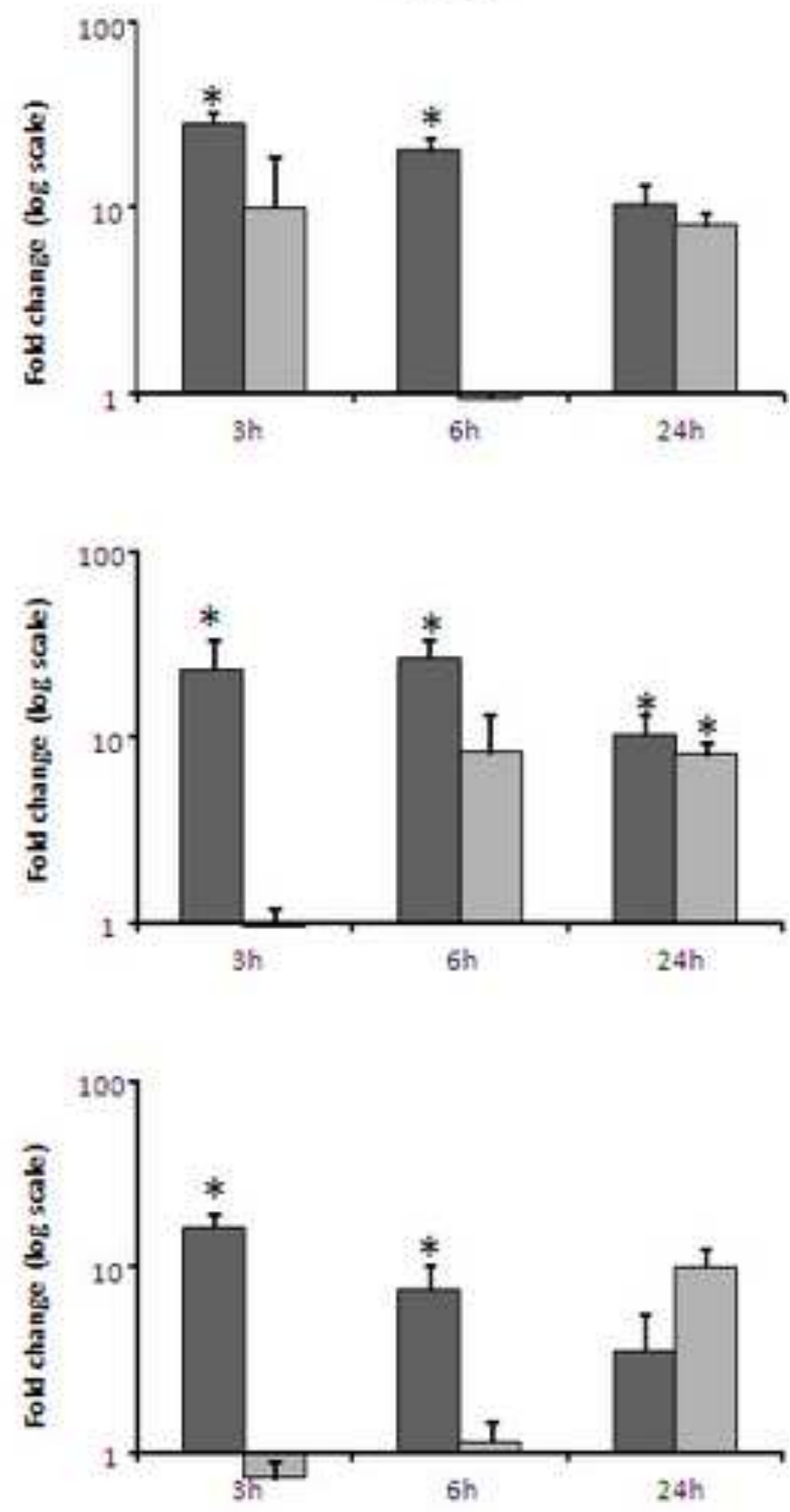